\title{
Positive and Negative Phases of the Wintertime North Atlantic Oscillation and Drought Occurrence over Europe: A Multitemporal-Scale Approach
}

\author{
J. IGNACIO LÓPEZ-MORENO \\ Climatic Change and Climate Impacts Group, University of Geneva, Geneva, Switzerland, and Instituto Pirenaico de Ecología, CSIC, \\ Zaragoza, Spain \\ Sergio M. Vicente-SERRANo \\ Instituto Pirenaico de Ecología, CSIC, Zaragoza, Spain
}

(Manuscript received 23 October 2006, in final form 1 August 2007)

\begin{abstract}
In this study, droughts are analyzed using the standardized precipitation index (SPI) at different time scales for all of Europe over the period 1901-2000. The SPI is calculated at different time scales (1-12 months), as are the average values that correspond to negative and positive phases of the North Atlantic Oscillation (NAO). The responses of droughts to the phases of the NAO vary spatially, but the response also depends on the month of the year and the time scale of the analysis. During the positive/negative phases, negative/positive SPI values are generally recorded in southern Europe, with the opposite pattern recorded in northern Europe. In certain regions, significant differences in the SPI are also recorded during spring, summer, and even autumn. In several regions, the magnitude of the average SPI anomalies is noticeably different for the positive and negative phases of the NAO, indicating the asymmetric response of droughts to the NAO. The unstable response of drought occurrence is also demonstrated, at different time scales, to positive and negative phases of the NAO throughout the twentieth century. During the second half of the twentieth century, there is a strengthening of the influence of the positive phases of the NAO on droughts. In contrast, the negative phases show a weaker influence on the SPI during the second half of the twentieth century. This pattern is related to changes in the wintertime sea level pressure fields associated with positive and negative phases of the NAO.
\end{abstract}

\section{Introduction}

Droughts are first-order hazards that affect Europe with a high frequency and intensity. Although droughts are complex and are related to a multitude of factors (Wilhite and Glantz 1985), they always have a climatic origin: below-average precipitation over the medium to long term. This climatic origin of droughts has led to significant interest in the behavior and characteristics of climatic droughts within Europe. Previous studies have focused on this topic, analyzing the spatial and temporal patterns of drought across the entire European continent (Briffa et al. 1994; Lloyd-Hughes and Saunders 2002b; Van der Schrier et al. 2006). These studies have

Corresponding author address: J. Ignacio López-Moreno, Instituto Pirenaico de Ecología (CSIC), Campus de Aula Dei, P.O. Box 202, Zaragoza 50080, Spain.

E-mail: nlopez@ipe.csic.es described interesting results in terms of analyzing the spatial and temporal patterns of drought using the Palmer drought severity index (PDSI; Palmer 1965).

However, the 9-12-month fixed time scale considered by the PDSI (Guttman 1998) limits the ability of the user to analyze certain characteristics of droughts and influences the results of the analysis, because the response of different water sources to drought is sensitive to the chosen time scale. Consequently, droughts must be considered a multiscale phenomenon. McKee et al. (1993) stated that usable water resources include soil moisture, groundwater, snowpack, river discharge, and storage reservoirs. The time interval between precipitation and the arrival of water into these subsystems varies as a function of the accumulated precipitation at different time scales (Changnon and Easterling 1989; Pandey and Ramasastri 2001). Thus, the time scale over which precipitation deficits accumulate is extremely important, and it functionally distinguishes different types 
of droughts, such as hydrological, agricultural, and environmental.

A temporal discrepancy generally exists between meteorological and hydrological droughts, because meteorological droughts extend in the form of hydrological droughts that appear several weeks/months after the meteorological drought is first recognized (Eltahir and Yeh 1999; Vicente-Serrano and López-Moreno 2005). It is therefore crucial to consider different time scales when analyzing climatic droughts in order to differentiate potential impacts on hydrological systems and sources of usable water.

Previous studies have also documented important spatial and temporal variability in droughts within $\mathrm{Eu}-$ rope (Briffa et al. 1994; Van der Schrier et al. 2006; Lloyd Hughes and Saunders 2002b). This variability is controlled by a number of atmospheric circulation patterns (Van der Schrier et al. 2006). The North Atlantic Oscillation (NAO) is the primary atmospheric circulation mode that determines the climate of Europe (Hurrell et al. 2003). The NAO is recognized throughout the entire year in Europe, although it also shows important seasonal variability. The NAO has a greater intensity and spatial coverage during winter (Hurrell et al. 2003). During positive phases of the NAO, dry conditions affect southern Europe, whereas increased precipitation affects northern Europe (e.g., Hurrell et al. 2003; Hurrell and Van Loon 1997; Trigo et al. 2002). The opposite pattern occurs during negative phases.

Recent studies have used running correlations to demonstrate that the strength of the relationship between surface climate and the NAO varies over time (Osborn et al. 1999; Chen and Hellström 1999; Slonosky et al. 2001). Jones et al. (2003) analyzed the mobile correlations between the NAO and four European temperature series from 1820. The authors showed that over the analysis period, obtained correlations show a gradual strengthening, peaking at between 0.7 and 0.9 during the $31 \mathrm{yr}$ centered on 1960, compared to values of 0.4 to 0.7 for the midnineteenth century. The authors suggested that this pattern might indicate a shift in climate behavior.

Although the influence of the NAO on European climate is well known from the results of a number of studies (e.g., Trigo et al. 2002; Hurrell and Van Loon 1997; Hurrell et al. 2003), the following questions remain to be answered: 1) How do the positive and negative phases of the NAO affect Europe-wide droughts? 2) How are the effects of the positive and negative phases propagated throughout the year in the form of droughts at different time scales? 3) What is the nature of spatial variations in these effects? 4) Has the influence of positive and negative phases of the NAO changed during the twentieth century? 5) What are the spatial patterns of this change? 6) What is the connection between these various issues concerning the influence of the NAO phases on sea level pressure (SLP) patterns and precipitation regimes throughout Europe?

This paper analyzes these issues for the whole European continent for the period of the twentieth century (1901-2000). The purpose of the paper is to assess whether the wintertime NAO behavior can be used to predict drought for the subsequent months and seasons. This topic is very important and of wide interest from both scientific and applied perspectives in terms of improving our ability to predict trends in water resources and managing integrated water resources across the entire European continent.

\section{Methodology}

\section{a. Database and spatial classification of Europe according to variability in precipitation}

In this analysis, we used a database of monthly gridded precipitation data at a resolution of $10^{\prime}$ for the entire European continent for the period of 1901-2000, as compiled by the Climate Research Unit of the University of East Anglia (information online at http://www. cru.uea.ac.uk/ timm/grid/TYN_SC_1_0.html). The monthly gridded database of precipitation covers the European countries to a longitude of $31.6^{\circ}$. The geographical region considered in this study can be consulted (see Figs. 2 and 3).

In relation to the quality and homogeneity of the precipitation data, before interpolation, the database was checked for inhomogeneities in the station records by the Climate Research Unit using an automated method that refines previous methods by using incomplete and partially overlapping records and by detecting inhomogeneities with opposite signs in different seasons. The method includes the development of reference series using neighboring stations (see details in Mitchell and Jones 2005). The dataset constitutes an advance over other products because it has a higher spatial resolution than other datasets of a similar temporal extent, it has longer temporal coverage than other products of a similar spatial resolution, and the construction method ensures that strict temporal fidelity is maintained. An intercomparison of this dataset with satellite-based precipitation data from the Climate Prediction Center (CPC) Merged Analysis of Precipitation (CMAP) dataset (Xie and Arkin 1997) has shown good agreement between the two datasets, in terms of both climatology and leading modes of precipitation variability (Zveryaev 2004). 
A precipitation-based classification of homogeneous areas was undertaken to retain the general temporal and spatial patterns of the monthly precipitation series. This classification was performed on the basis of a principal component analysis (PCA) of the monthly precipitation series (Jolliffe 1990). We performed the PCA in $\mathrm{S}$ mode to obtain the general temporal patterns of precipitation. This mode provides loading values that correspond to each pattern, which can then be represented spatially to determine their spatial representativeness. For the PCA, we selected a correlation matrix. The number of components was selected in accordance with the total explained variance $(70 \%)$. Finally, the components were rotated to redistribute the final explained variance and to obtain more stable, physically robust patterns (Richman 1986). For this purpose, we used the Varimax rotation, which is the most widely applied option because it provides clearer and physically explainable patterns (Jolliffe 1990).

The spatial classification of monthly precipitation patterns in Europe was carried out using the factorial loadings for each component, grouping the observatories by the maximum loading rule, following the similar approach used by previous authors (e.g., Karl and Koscielny 1982; Vicente-Serrano 2006). Once homogeneous areas were identified, a regional precipitation series for each area was formed using the averages of monthly precipitation records at each grid point.

To analyze the observed atmospheric patterns for each year according to the phases of wintertime NAO, we used the database of monthly grids of SLP provided by the National Centers for Environmental Prediction-National Center for Atmospheric Research (NCEP-NCAR; information online at http://dss.ucar. edu/datasets/ds010.1/) at a resolution of $5^{\circ}$ (Trenberth and Paolino 1980). This database is unique in that it has a complete record and covers the long period analyzed in the present paper (1901-2000).

\section{b. Calculation of the drought index at different time scales}

Among the drought indices developed in recent decades (Heim 2002), the standardized precipitation index (SPI) and PDSI are the most widely used methods for drought analysis.

In this paper, we have analyzed droughts using the SPI (McKee et al. 1993) at different time scales. The SPI has a number of advantages over other indices (Guttman 1998; Keyantash and Dracup 2002): it employs a moving average that facilitates spatial comparability (Guttman 1998), it is valid for any season, and the results are not affected by topography (Lana et al.
2001). In addition, the length of the precipitation record and the period used for calculation do not significantly affect the final calculation of the SPI (Wu et al. 2005).

Redmond (2002) demonstrated that the SPI at time scales between 6 and 12 months shows a stronger correlation with the PDSI $(\sim 0.9)$ because precipitation is the main variable that is used in determining drought conditions (Keyantash and Dracup 2002), and it determines the majority of the variability in the PDSI (Guttman et al. 1992). The SPI enables estimates of the duration, magnitude, and intensity of droughts to be calculated at different time scales, thereby enabling quantification of different drought types, including hydrological, agricultural, and environmental droughts. The SPI calculated at time scales between 3 and 6 months can be considered an agricultural drought index (Hayes et al. 1999), because it enables the monitoring of moisture conditions within vegetation and soil ( $\mathrm{Ji}$ and Peters 2003; Vicente-Serrano et al. 2006). The SPI calculated at time scales between 6 and 12 months is considered a hydrological drought index, and it is useful for monitoring surface water resources (VicenteSerrano and López-Moreno 2005).

The SPI has been used in several different regions because of its high degree of spatial adaptability to different climatic conditions (e.g., Hayes et al. 1999; Bordi et al. 2004; Loukas and Vasiliades 2004). Lloyd-Hughes and Saunders (2002b) demonstrated the performance of the SPI in analyzing the spatial and temporal patterns of droughts across the entire European continent.

The SPI calculation starts with precipitation calculation over a range of time scales. The total precipitation $X_{i, j}^{k}$ in a given month $j$ and year $i$ depends on the time scale chosen, $k$. For example, the SPI for 1 month in a particular year $i$ with a 12-month time scale is calculated according the following formulas:

$$
\begin{aligned}
& X_{i, j}^{k}=\sum_{l=13-k+j}^{12} w_{i-1, l}+\sum_{l=1}^{j} w_{i, l}, \quad \text { if } j<k, \quad \text { and } \\
& X_{i, j}^{k}=\sum_{l=j-k+1}^{j} w_{i, l}, \quad \text { if } j \geq k,
\end{aligned}
$$

where $w_{i, l}$ is precipitation in the first month of year $i$ $(\mathrm{mm})$.

The frequency distributions of the precipitation series show significant changes that depended on the time scale (Vicente-Serrano 2006). Nevertheless, among different models the Pearson III shows an enhanced adaptability to precipitation series at different time scales (Guttman 1999; Vicente-Serrano 2006). In this paper, Pearson III distribution has been chosen to calculate SPI for time scales from 1 to 12 months. 
The probability density function of a Pearson III distributed variable is expressed as

$$
f(x)=\frac{1}{\alpha \Gamma(\beta)}\left(\frac{x-\gamma}{\alpha}\right)^{\beta-1} e^{-(x-\gamma / \alpha)},
$$

where $\alpha, \beta$, and $\gamma$ are the shape, scale, and origin parameters, respectively, for precipitation values $x>0$; and $\Gamma(\beta)$ is the gamma function of $\beta$.

Parameters of the Pearson III distribution can be obtained following different procedures. Among them, the L-moments procedure is the most robust approach (Sankarasubramanian and Srinivasan 1999); $\tau_{3}$ and $\tau_{4}$ are the L coefficients of skewness and kurtosis, respectively, and are calculated as follows:

$$
\begin{gathered}
\tau_{3}=\frac{\lambda_{3}}{\lambda_{2}}, \\
\tau_{4}=\frac{\lambda_{4}}{\lambda_{2}} .
\end{gathered}
$$

Here, $\lambda_{2}, \lambda_{3}$, and $\lambda_{4}$ are the $\mathrm{L}$ moments of the precipitation series. These are obtained from probabilityweighted moments (PWMs), using the following formulas:

$$
\begin{aligned}
& \lambda_{1}=\alpha_{0}, \\
& \lambda_{2}=\alpha_{0}-2 \alpha_{1}, \\
& \lambda_{3}=\alpha_{0}-6 \alpha_{1}+6 \alpha_{2}, \\
& \lambda_{4}=\alpha_{0}-12 \alpha_{1}+30 \alpha_{2}-20 \alpha_{3} .
\end{aligned}
$$

The PWMs of order $s$ are calculated as

$$
\alpha_{s}=\frac{1}{N} \sum_{i=1}^{N}\left(1-F_{i}\right)^{s} x_{i}
$$

$x_{i}$ is the data from a given precipitation series and $F_{i}$ is the frequency estimator. Here, $F_{i}$ is calculated following the approach of Hosking (1990):

$$
F_{i}=\frac{i-0.35}{N},
$$

where $i$ is the range of observations arranged in rising order, and $N$ is the number of data points.

When L moments are calculated, the parameters of the Pearson III distribution can be obtained following Hosking (1990).

If $\tau_{3} \geq 1 / 3$, then $\tau_{m}=1-\tau_{3}$, and $\beta$ can be obtained using the following:

$$
\beta=\frac{\left(0.36067 \tau_{m}-0.5967 \tau_{m}^{2}+0.25361 \tau_{m}^{3}\right)}{\left(1-2.78861 \tau_{m}+2.56096 \tau_{m}^{2}-0.77045 \tau_{m}^{3}\right)} .
$$

If $\tau_{3}<1 / 3$, then $\tau_{m}=3 \pi \tau_{3}^{2}$, and $\beta$ can be obtained using the following:

$$
\begin{aligned}
& \beta=\frac{\left(1+0.2906 \tau_{m}\right)}{\left(\tau_{m}+0.1882 \tau_{m}^{2}+0.0442 \tau_{m}^{3}\right)}, \\
& \alpha=\sqrt{\pi} \lambda_{2} \frac{\Gamma(\beta)}{\Gamma(\beta+1 / 2)}, \\
& \gamma=\lambda_{1}-\alpha \beta .
\end{aligned}
$$

According Pearson III distribution, the probability distribution function of $x$ is given by

$$
F(x)=\frac{1}{\alpha \Gamma(\beta)} \int_{\gamma}^{x}\left(\frac{x-\gamma}{\alpha}\right)^{\beta-1} e^{-(x-\gamma / \alpha)} .
$$

Pearson III distribution is not defined for $x=0$, which is a drawback because precipitation series may include months in which there is no precipitation. With this in mind, an adapted statistic $H(x)$ can be calculated using the following formula:

$$
H(x)=q+(1-q) F(x),
$$

where $q$ is the probability of zero precipitation; $q$ can be calculated simply as $m / n$, where $n$ is the total number of months and $m$ is the number of months with no precipitation.

After calculating $H(x)$, the mean is standardized as 0 with a standard deviation of 1 . This standardized variable is interchangeable with the SPI, and is commensurable with other SPI values over time and space. An SPI of 0 indicates precipitation corresponding to $50 \%$ of the accumulated probability according to the Pearson III distribution.

To transform $H(x)$ and obtain SPI, the following approach formulated by Abramowitz and Stegun (1965) is used:

$$
\begin{gathered}
\mathrm{SPI}=W-\frac{C_{0}+C_{1} W+C_{2} W^{2}}{1-d_{1} W+d_{2} W^{2}+d_{3} W^{3}}, \\
W=\sqrt{-2 \ln (P)} \text { for } P \leq 0.5 .
\end{gathered}
$$

Here, $P$ is the probability of exceeding a determined precipitation value, $P=1-H(u)$.

If $P>0.5, P$ is replaced by $1-P$ and the sign of the resultant SPI is switched.

The constants are $C_{0}=2.515517, C_{1}=0.802853$, $C_{2}=0.010328, d_{1}=1.432788, d_{2}=0.189269$, and $d_{3}=0.001308$.

\section{c. Identification of positive and negative phases of the wintertime $N A O$}

NAO indices are obtained for the period of instrumental information using SLP data (Hurrell et al. 2003). The following two different procedures can be 
used to quantify the NAO: (i) SLP grids and multivariate statistics (PCA), and (ii) SLP differences between single stations located near the main centers of the action that characterize the NAO. Wallace (2000) concluded that station-based indices do not provide an optimal representation of the NAO because of seasonal displacement of the Icelandic low and the Azores anticyclone. Nevertheless, the use of PCA to define the NAO index has important shortcomings that are mainly related to the fact that spatial patterns and corresponding PC time series are dependent on the size of the window used in the analysis (Trigo et al. 2002). Moreover, Osborn et al. (1999) showed that NAO indices derived from PCA or single stations show similar time evolutions, with correlations in the range of $0.84-0.96$. Their analysis showed that the interannual variability of the wintertime NAO is not affected by the method employed to calculate the NAO index.

In the present paper, we chose the NAO index created from the difference between the standardized pressure anomalies measured at Gibraltar (south of Spain) and Reykjavík (Iceland). The advantage of using these stations is discussed in depth by Jones et al. (1997), who noted that Gibraltar appears to better represent the southern part of the NAO dipole than other commonly used stations, such as Lisbon or Ponta Delgada in the Azores. Osborn et al. (1999) showed that the ratio of interdecadal to interannual variance is greater for those indices using the southern node of information, such as Gibraltar, than those that used information from the farther west (e.g., Azores). Moreover, Hurrell (1995) and Jones et al. (2003) showed that a southwest European location used to calculate the NAO correlated slightly better with station and precipitation series across Europe than information from the Azores used to calculate the NAO index. The NAO index was compiled by the Climate Research Unit of the University of East Anglia (online at http://www.cru. uea.ac.uk/cru/data/nao.htm) between 1821 and 2007 . We used this index for the present study and we calculated the average wintertime NAO index (DecemberMarch), because the NAO has higher activity at this time (Hurrell et al. 2003). Interdecadal variability of the NAO appears to be the most coherent when the December-March season is used, more so than using other months (Osborn et al. 1999).

Following Muñoz-Díaz and Rodrigo (2004), we calculated the average and standard deviation of the wintertime NAO index between 1901 and 2000, because the Gaussian nature of the NAO index enables us to establish the symmetry of the index values around the average. Figure 1 shows a frequency histogram of the wintertime NAO index from 1901 to 2000, for which

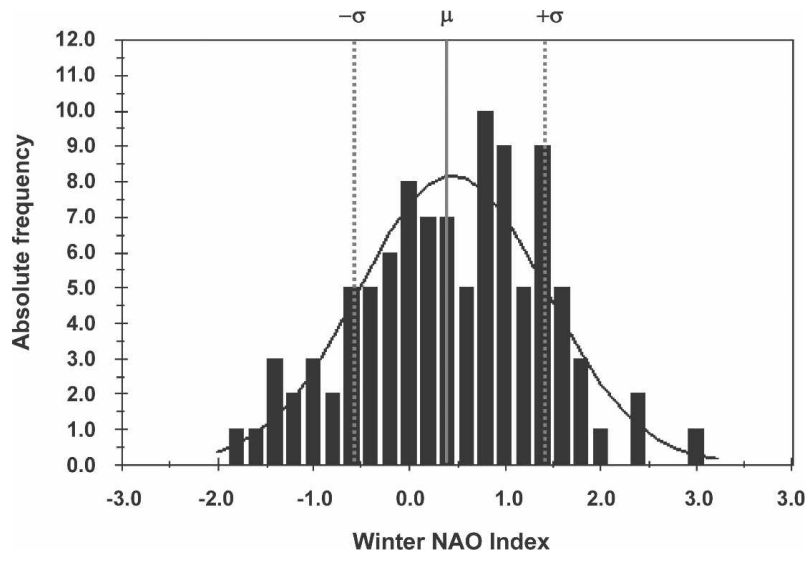

FIG. 1. Frequency histogram of the winter NAO index is shown (December-March). Vertical solid and dotted lines indicate the average and \pm 1 standard deviation.

the average value is 0.45 . We identified positive and negative phases as those values that differed from the average by at least $\pm \sigma$. On this basis, $16 \mathrm{yr}$ were identified as having positive phases and 16 as having negative phases. The positive phases are in 1903, 1905, 1910, 1913, 1920, 1925, 1957, 1961, 1967, 1983, 1989, 1990, 1992, 1994, 1995, and 2000; the negative phases are in 1917, 1936, 1940, 1941, 1947, 1955, 1956, 1962, 1963, 1964, 1965, 1969, 1971, 1977, 1979, and 1996.

\section{d. Statistical analysis}

For both positive and negative phases of the NAO, we calculated the average values of the SPI at different time scales for the different homogeneous regions. We then used the Wilcoxon-Mann-Whitney rank-sum test (Siegel and Castelan 1988; Wilks 2006) to determine whether the SPI averages at different time scales represented significantly humid or dry conditions during the positive and negative phases. The Wilcoxon-MannWhitney rank-sum test is based on ranks that do not require normally distributed samples; it is slightly less powerful than parametric tests such as the $t$ test (Helsel and Hirsch 1992). Although the SPI is a normalized variable for the entire series, the normality of the sample cannot be guaranteed, and the distribution may be biased when a sample of years is extracted (i.e., the SPI values during positive and negative years). For this reason, the use of a nonparametric test is more convenient.

The sample that comprised SPI values for each of the months of the positive/negative years was compared with the values of SPI for months of normal years (those years within the rank $-\sigma \leq \mathrm{NAO} \geq+\sigma$ ) and months of years with the opposite sign. The significance level was established at $\alpha<0.05$. 


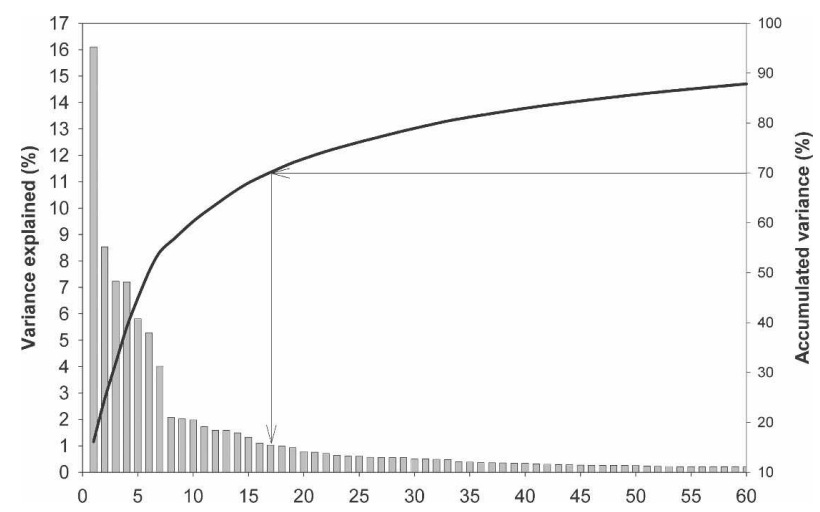

FIG. 2. Results of the PCA from the monthly European precipitation series are shown. The total variance explained by each component (columns) and the total accumulated variance (black line) are shown.

Finally, we analyzed differences in the SPI averages during NAO phases between the periods of 1901-50 and 1951-2000 to determine possible temporal changes in the influence of NAO phases on drought conditions. The Wilcoxon-Mann-Whitney rank-sum test was also used in this analysis.

\section{Results}

\section{a. Homogeneous European regions identified from monthly precipitation series (1901-2000)}

Figure 2 shows the results of the PCA of precipitation series for the entire European continent. The first 17 rotated components explain more than $70 \%$ of the variance, while the 18th component explains less than $1 \%$ of the total variance. Accordingly, the first $17 \mathrm{com}$ ponents were retained for further analysis. Between the first and second components the most important decrease is identified, but between the seventh and eighth components there is also a sharp decrease in the total variance explained by each component. This indicates that the first seven components have a higher spatial representativeness.

Figure 3 shows the spatial distribution of the rotated loadings that correspond to each component (correlation between each rotated component and the time series of monthly precipitation for each pixel). This allows us to identify the areas represented by each component.

Because loadings do not overlap, they enable the identification of spatially coherent homogeneous regions. Using the maximum loading rule, it is possible to classify the European region in terms of the 17 selected regions. Figure 4 shows the homogeneous regions obtained following this approach. Each region is repre- sented by a unique series of monthly precipitation data for the period of 1901-2000 in terms of the average value of whole pixels of the region of interest.

Figure 5 shows the temporal evolution of annual precipitation values in the 17 regions. We analyzed these data for significant trends over the entire period and for significant differences between the 1901-50 and 19012000 periods. In this analysis, we used the nonparametric Spearman test because of its advantages over other tests (Lanzante 1996). Significant trends $(\alpha<0.05)$ over the period of 1900-2000 were only recorded in regions 1 (Finland and Sweden; Rho $=0.368$ ), 5 (Ireland and United Kingdom; Rho $=0.21$ ), 8 (central Norway; Rho $=0.34), 10$ (westernmost Norway; Rho = 0.25 ), and 12 (north Norway; Rho $=0.44$ ). All of these regions are located in northern Europe (Scandinavia and the British Isles), and all show a temporal increase in precipitation rates. Nevertheless, we only found significant differences between the average precipitation values for 1901-50 and 1951-2000 (Wilcoxon-MannWhitney test, $\alpha<0.05$ ) for regions 1 (Finland and Sweden), 8 (central Norway), and 12 (northern Norway).

Figure 6 shows examples of the evolution of the SPI at time scales of $1,3,6$, and 12 months for regions 5 (Ireland and United Kingdom) and 6 (Iberian Peninsula). The frequency of dry and humid periods changes as a function of time scale. The longer time scales (e.g., 12 months) show less frequent but longer dry periods $($ SPI $<0)$. Shorter time scales (e.g., 3 months) show an increase of the frequency of dry periods but a reduction in their duration.

\section{b. Response of drought to positive and negative phases of the NAO}

Figure 7 shows a detailed example of the average values of the SPI at time scales of 1, 3, 6, and 12 months, corresponding to the positive (Fig. 7a) and negative (Fig. 7b) phases of the NAO in region 5 (Ireland and the United Kingdom). Positive averages indicate humid conditions, whereas negative values are indicative of droughts. Significant differences in the average values vary in magnitude and appear in different months, depending on whether they correspond to positive or negative phases. There are also important differences related to the time scale of the SPI.

Figure 8 summarizes this behavior for the 17 regions and the 12 time scales of the SPI (1-12 months). Average values of the SPI corresponding to the positive (Fig. 8a) and negative (Fig. 8b) phases of the NAO are shown for the period between December (1) and November (12). The number of each region corresponds to that indicated in Fig. 4. In general, there are marked differences between different regions, time 

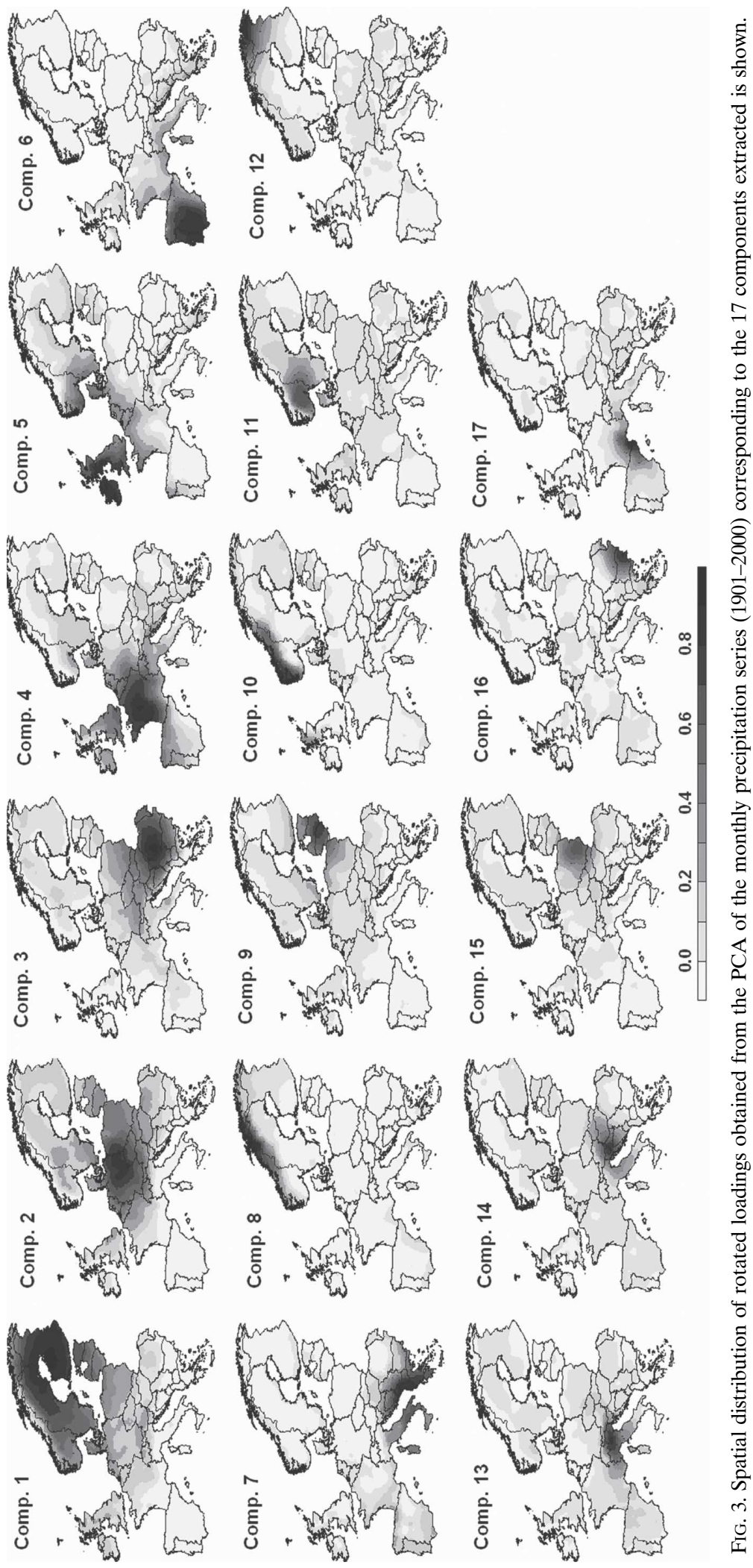


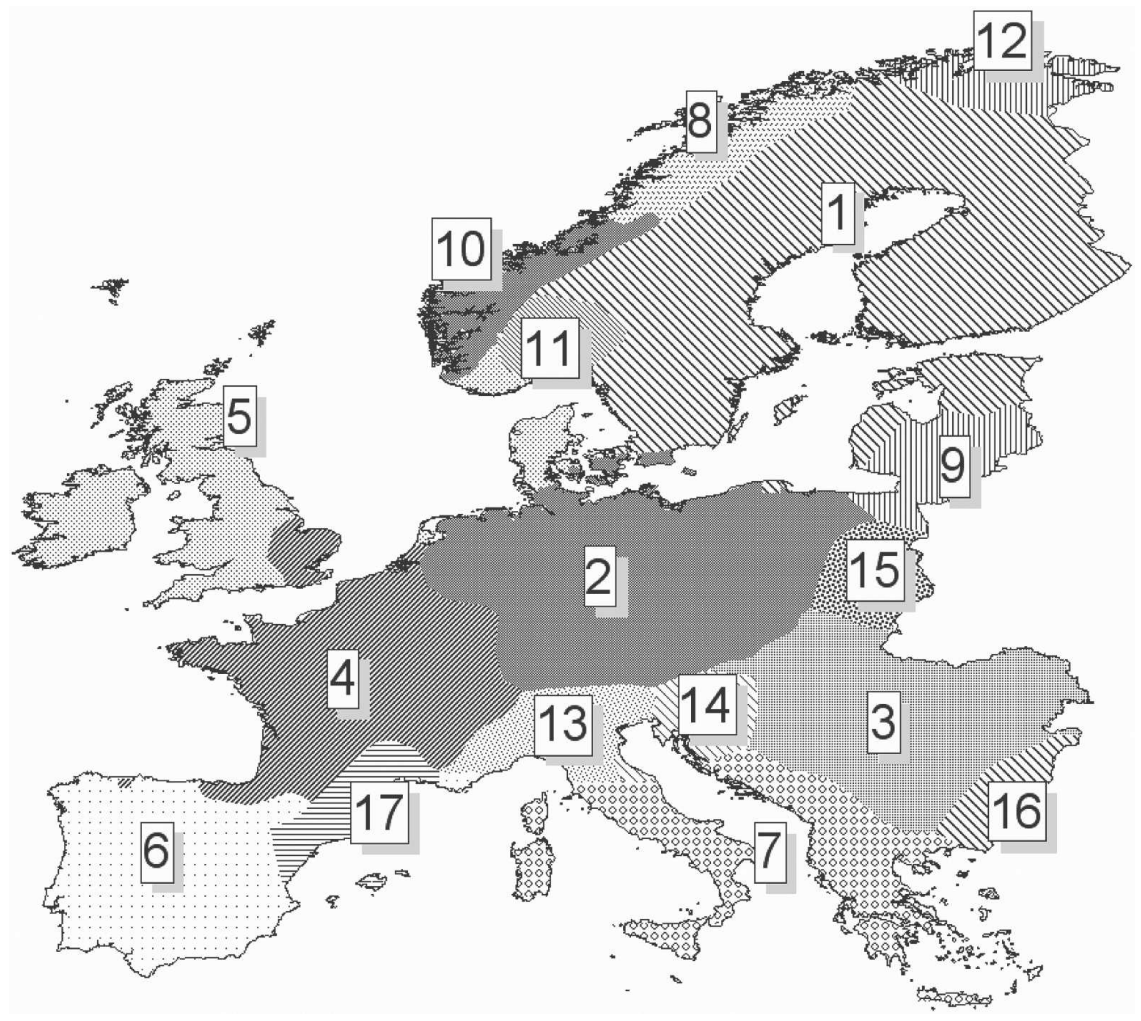

FIG. 4. Homogeneous European regions according to the monthly precipitation obtained by means of PCA and following the maximum loading rule.

scales of the SPI, and positive and negative phases of the NAO. The most significant results are listed below:

- In region 1 (large areas of Fennoscandia and the Baltic states), droughts are associated with negative NAO phases, whereas humid conditions occur during positive phases. Nevertheless, the response varies according to the month of the year and the time scale of the SPI. During winter and spring months, significant differences in the averages are only evident at short time scales $(<4$ months). In summer and autumn, strong positive (negative) SPI averages correspond to positive (negative) phases. These anomalies are identified for time scales of between 6 and 12 months, indicating the propagation of NAO effects throughout the year when analyzed using long time scales for the SPI.

- In region 3 (central Balkans), averages of the SPI are dominantly negative (positive), corresponding to positive (negative) phases of the NAO. Nevertheless, significant differences are only recorded between January and May for short time scales of the SPI. In this region, the behavior of the NAO is quasi symmetrical between positive and negative phases, showing similar months/time scales that record significant differences in average SPI values.
- In region 5 (a large part of the British Isles), the sign and magnitude of SPI values are clearly linked to the occurrence of positive and negative phases of the wintertime NAO. Droughts occur during the negative NAO, with above-average precipitation during positive phases. Nevertheless, the response of SPI to the positive and negative phases is asymmetrical. The positive average SPI identified during the positive phases shows a greater magnitude than the negative averages recorded during the negative phases. Moreover, the time scales for which important anomalies are identified change noticeably as a function of the sign of the phases. Positive phases generally record significant differences for most months and time scales. During negative phases, the statistically significant differences between SPI averages are strongly dependent on the month and time scale employed.

- In region 6 (Iberian Peninsula), negative (positive) averages of the SPI are associated with positive (negative) phases of the NAO. This region has the highest recorded anomalies in the SPI that are associated with positive and negative phases of the NAO. We also observe propagation of the averages throughout the year when considering long time 

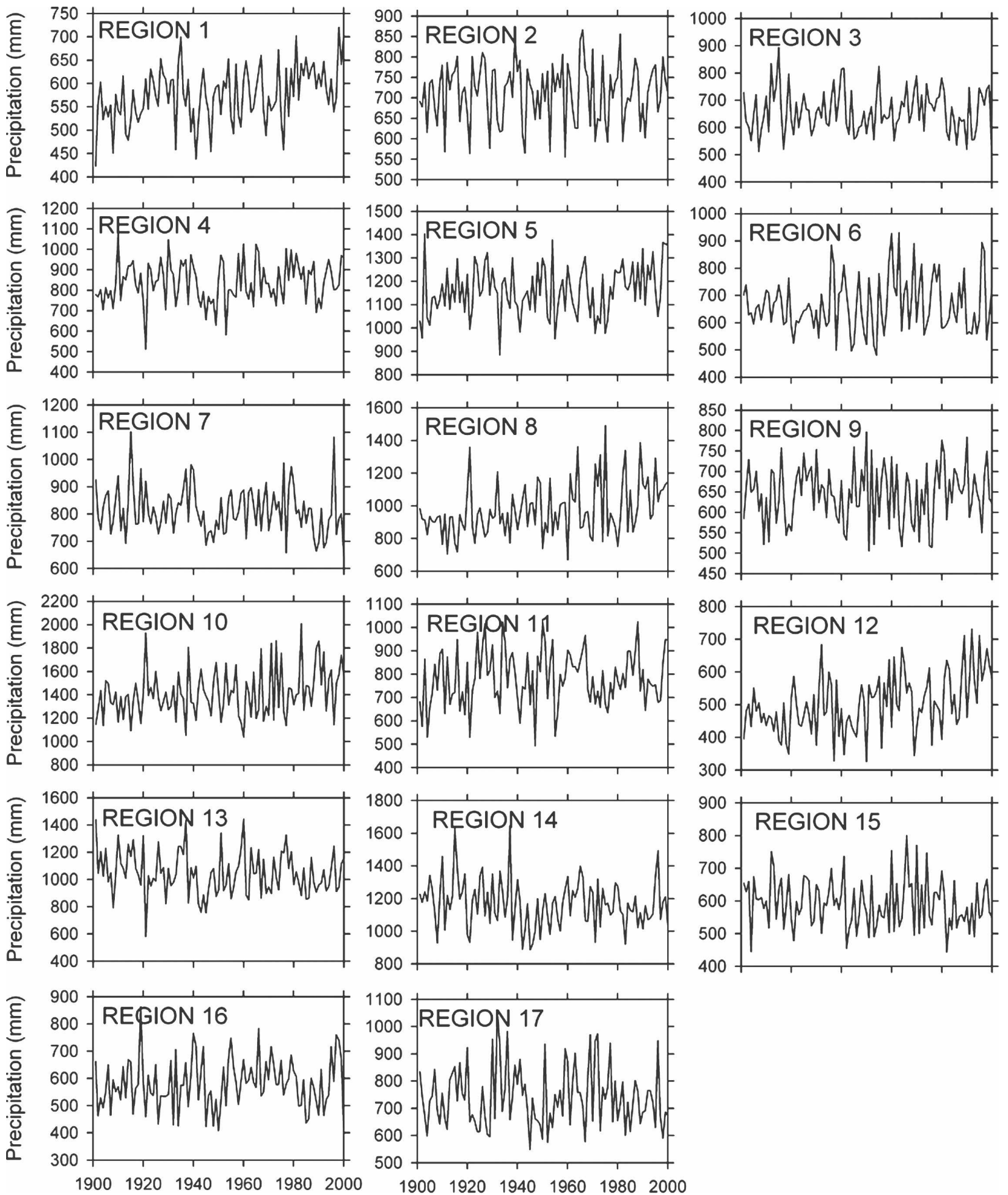

FIG. 5. Evolution of the annual precipitation in the 17 homogeneous regions is shown (1901-2000). The number of each region corresponds to those indicated in Fig. 4. 
A)

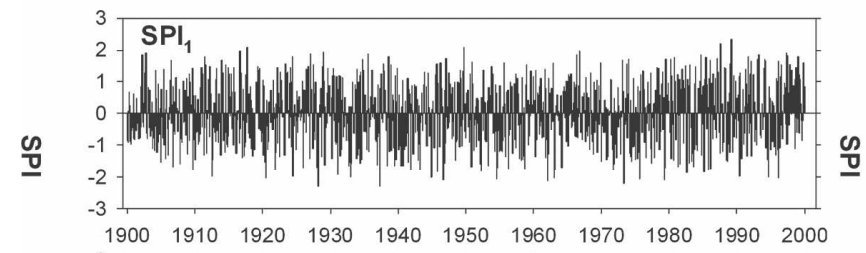

$\underline{\underline{0}}$
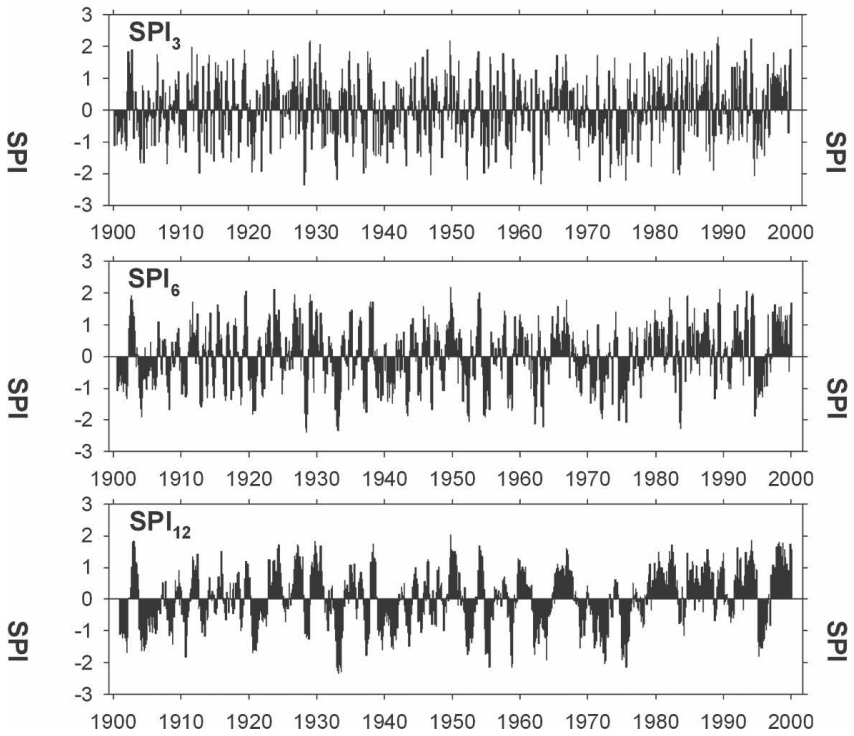

B)

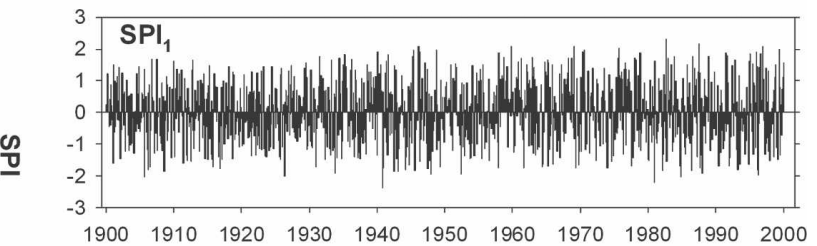

$\begin{array}{lllllllllll}1900 & 1910 & 1920 & 1930 & 1940 & 1950 & 1960 & 1970 & 1980 & 1990 & 2000\end{array}$

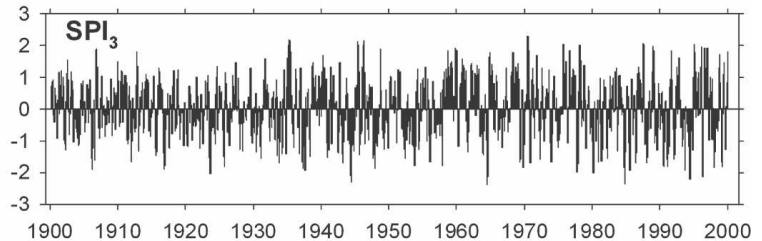

$\begin{array}{lllllllllll}1900 & 1910 & 1920 & 1930 & 1940 & 1950 & 1960 & 1970 & 1980 & 1990 & 2000\end{array}$

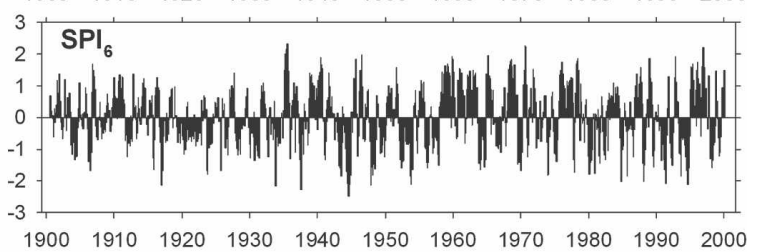

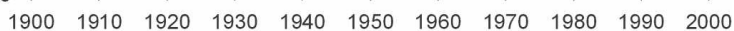

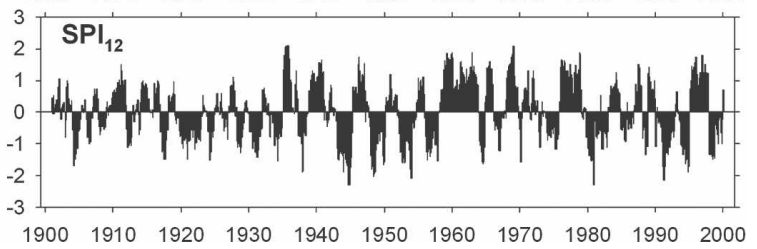

FIG. 6. Evolution of the SPI at the time scales of 1,3, 6, and 12 months in regions (a) 5 (Ireland and United Kingdom) and (b) 6 (Iberian Peninsula) between 1901 and 2000.

scales for the SPI. The magnitude of the anomalies is greater during negative phases, suggesting an asymmetric behavior in the response of the SPI to the wintertime NAO.

- Region 7 (south Italy, Greece, and large areas of the Balkans) also shows negative (positive) SPI averages that correspond to positive (negative) phases of the NAO. For this region, the magnitude and seasonal distribution of droughts during positive phases is very similar, or even more intense, to that observed for region 6 (Iberian Peninsula); however, the magnitude of positive and significantly different SPI averages identified during the negative phases of the NAO is less than that observed for region 6 . Thus, the similar (but opposite) behavior observed in the averages of SPI between the positive and negative phases of the NAO suggests a more linear response to the NAO than that observed for region 6.

- In region 8 (central Norway), there is a marked asymmetric response to the NAO. During positive phases of the NAO, significant positive averages of SPI are recorded as a function of the month of the year for time scales ranging from 1 to 11 months. During negative phases, average negative values dominate, but with a lesser magnitude; this does not suggest the occurrence of climatic droughts.

- Region 10 (westernmost Norway) shows a clear response of the SPI to positive and negative phases of the NAO: positive (negative) averages are associated with positive (negative) phases. The observed pattern shows the propagation of the effects of the NAO throughout the year for the longest time scales of the SPI.

- Regions 16 (eastern Bulgaria and Romania) and 17 (the south of France and northeast Spain) show the same behavior as that recorded for most of southern Europe: negative (positive) SPI averages associated with positive (negative) phases of the NAO. In region 17 , the SPI shows a symmetrical response to positive and negative NAO phases. In contrast, positive phases recorded for region 16 show average SPI values that are of lower magnitudes, and there are fewer months and time scales for which the average values are significantly different to those observed for negative phases.

Figure 9 shows an example for a certain time scale and month: the average of the SPI at a time scale of 12 

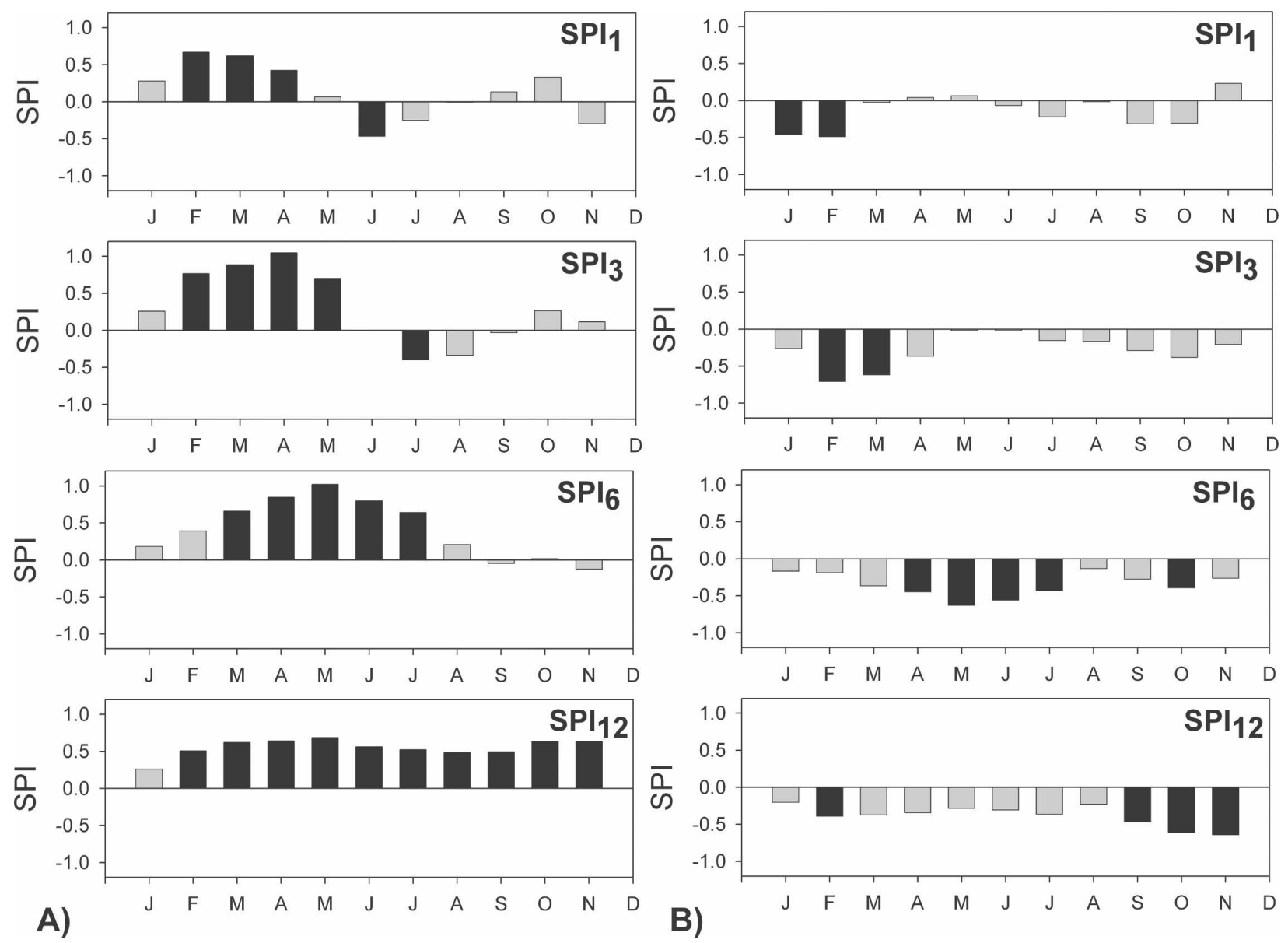

FIG. 7. Average values of the SPI at the time scales of 1,3,6, and 12 in different months, corresponding to (a) positive and (b) negative extreme phases of the NAO in the region 5 (Ireland and United Kingdom). Black columns indicate significant differences $(\alpha<0.05)$ in the average values regarding the rest of years (normal years and years with the opposite sign).

months in August during the positive and negative phases of the NAO. The map was obtained by calculating the SPI from the precipitation series for each $10^{\prime}$ pixel. Negative averages are recorded in southern Europe during positive phases; these are significantly different to those observed during other years that are identified in areas of southern Europe, mainly within the Iberian Peninsula and areas within the Balkans. During negative phases, the SPI is dominantly positive in southern Europe, and the extent of areas with significant differences in SPI is greater than that observed (with the opposite sign) during positive phases. In northern Europe, positive phases have larger areas with significant differences in the average SPI compared to other years (normal and opposite sign) than negative phases. Thus, in both cases, the response is more important during the phases that cause high precipitation (positive in northern Europe and negative in southern Europe). However, lines that delineate significant dif- ferences in the average SPI indicate a high risk of persistent droughts over the central Iberian Peninsula, southern Greece, Italy, and the Adriatic coast during positive NAO phases. During negative NAO phases, the affected areas are northwestern parts of the United Kingdom, western and southeastern Finland, and the Baltic states.

Our results indicate that the effect of the positive and negative phases of the NAO on the SPI is not solely restricted to the winter months. To explain why significant differences in SPI are recorded in spring, summer, and even autumn, we analyzed the influence of the positive and negative phases of the wintertime NAO on atmospheric circulation during different months of the year. To achieve this, we calculated the average SLP anomalies (differences from the average) for each month of the year (December-November) during positive and negative phases of the wintertime NAO. 

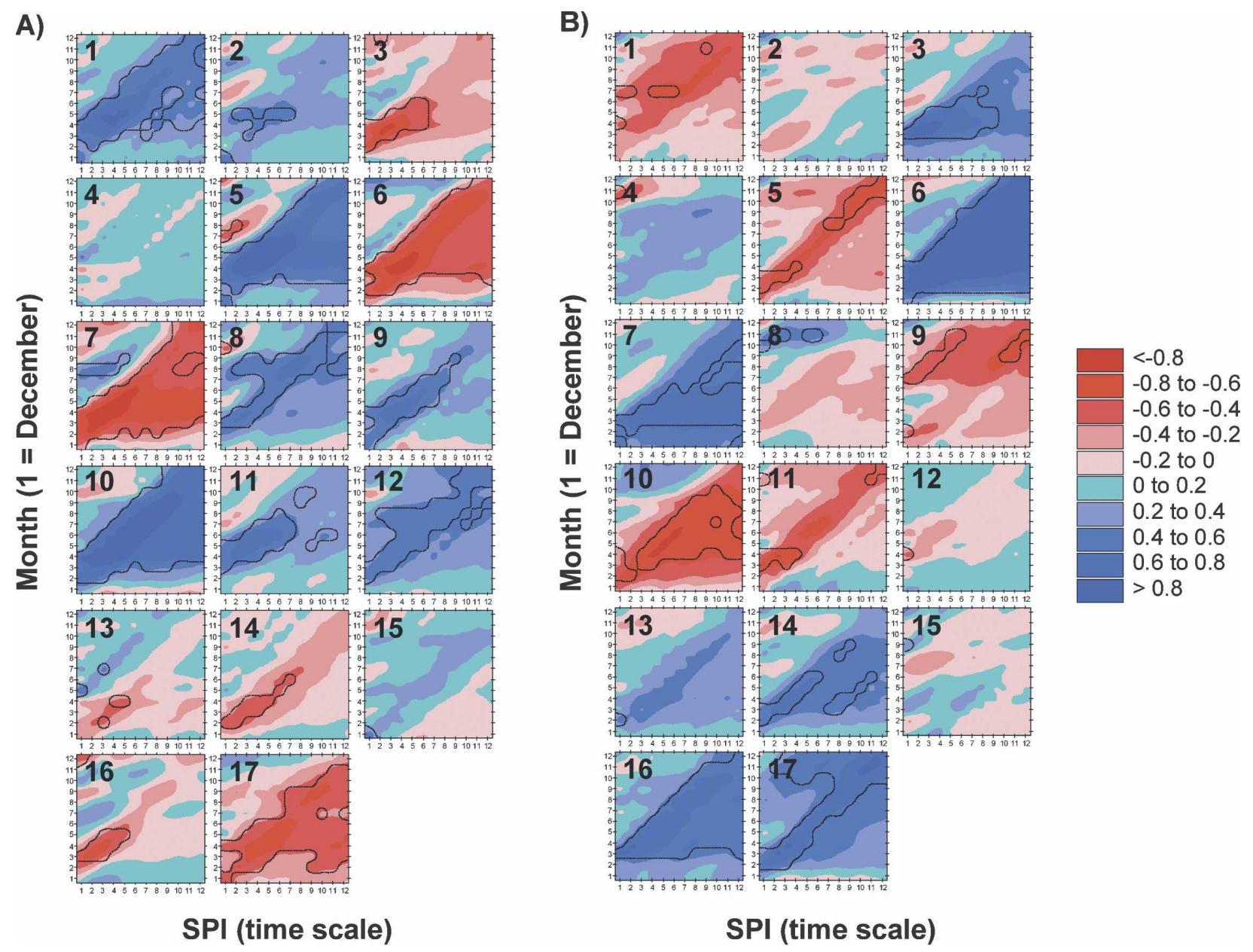

FIG. 8. Average values of SPI are shown at time scales from 1 to 12 months between December (1) and November (12) during the (a) positive and (b) negative NAO years in the 17 homogeneous regions. Black lines indicate significant differences $(\alpha<0.05)$ between the average SPI during the positive/negative years and the rest of years (normal years and the opposite sign).

Figures 10 and 11 show the anomalies calculated for each month during the positive and negative phases, respectively. A clear average configuration of SLP anomalies is only recorded during the winter months, when positive SLP anomalies dominate in southern Europe during positive phases; negative SLP anomalies are recorded for northern Europe. During negative phases, the opposite pattern is recorded in winter months. Throughout the rest of the year, there are no atmospheric configurations that clearly affect the spatial distribution and total amount of precipitation. Therefore, the observed influence of positive and negative phases of the NAO on droughts during a number of the months of the year cannot be explained by the influence of the NAO on atmospheric circulation, and hence on precipitation and drought conditions. Thus, the influence of positive and negative phases of the NAO on droughts recorded during several months of the year must directly relate to the influence of these phases on wintertime precipitation.

Figure 12 shows monthly averages of precipitation for the entire study period (1901-2000) and for the years that correspond to the positive and negative phases of the wintertime NAO. It is evident that regions for which the positive and negative phases of the NAO have a greater impact on droughts show clear differences in the average precipitation for positive and negative phases. Areas for which drought conditions at different time scales are identified for most of the months of the year during positive phases [the Iberian Peninsula (region 6), the Balkans (region 3), and south Italy (region 7)] show noticeable differences in the average December-March precipitation recorded during positive and negative phases. The same trend (but with opposite sign) is also recorded for regions for which negative phases lead to droughts [e.g., the United King- 


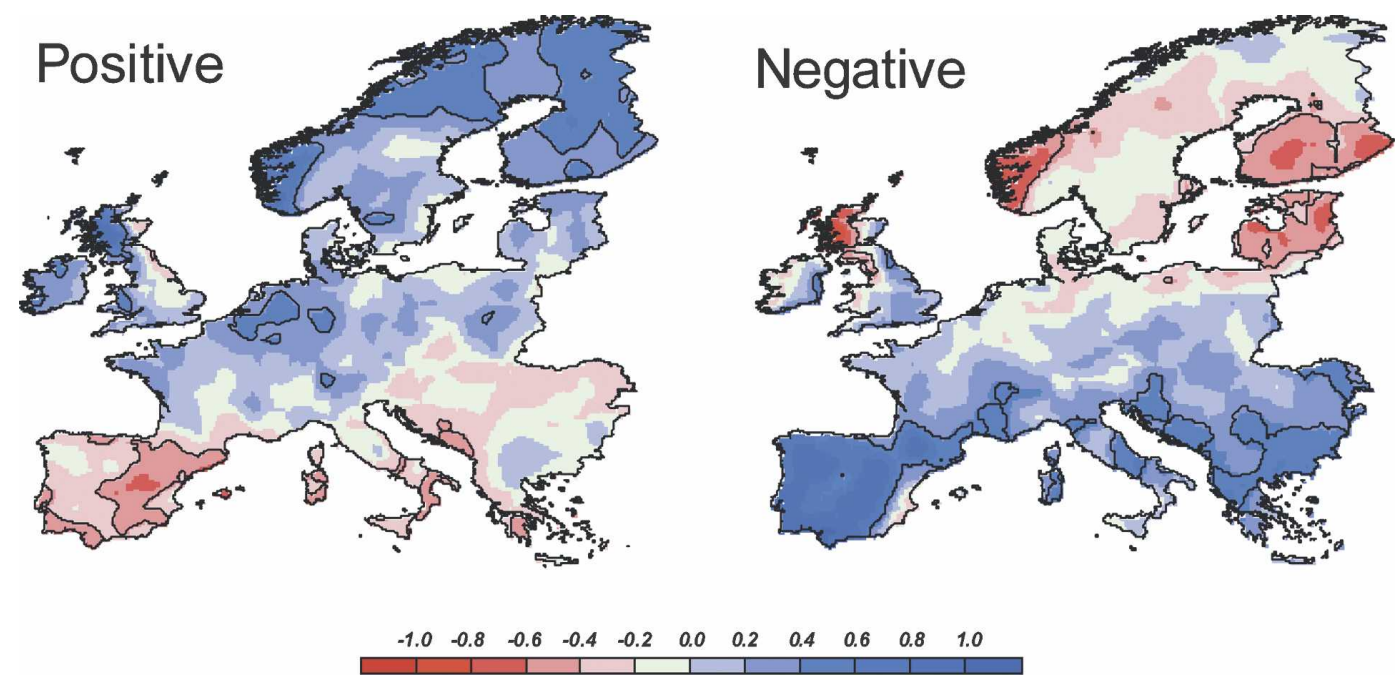

FIG. 9. Average values of SPI (12 months) in August during the positive and negative phases of the winter NAO. Dotted lines indicate significant differences between the averages of SPI during the positive/negative phases of the NAO and the rest of the years (normal and the opposite sign).

dom and Ireland (region 5) and Scandinavia (regions 1, 10, and 11)]. In these regions, the average precipitation in winter is higher during positive phases, with large differences recorded between the positive and negative phases.

\section{c. Temporal differences in drought response to positive and negative phases of the $N A O$ (1901-50 versus 1951-2000)}

Figure 13 shows differences in SPI values for the periods of 1951-2000 and 1901-50, at time scales from 1 to 12 months, corresponding to positive (Fig. 13a) and negative (Fig. 13b) phases of the wintertime NAO index. Important differences between the two periods are recorded in several regions, indicating temporal changes in the influence of positive and negative phases of the NAO on droughts. This behavior also varies for different time scales of SPI and for positive and negative phases of the NAO. The main results are indicated below:

- Region 1 (large areas of Finland and Sweden) shows a reinforcement of the influence of positive phases of the NAO on the SPI at different time scales. This indicates a general decrease in drought conditions during the second half of the twentieth century. The same pattern is identified for regions 8 (northern and central Norway), 9 (areas of Lithuania, Latvia, and Estonia, and northeastern Poland), 10 (westernmost Norway), and 12 (northern Norway). Figure 14 shows, as a representative example, the average values of the SPI at the time scale of 12 months for August during the positive and negative phases of the NAO. The figure shows data for the periods of 1901-
50 and 1951-2000, as well as differences between the two periods. During positive phases in the period of 1901-50, no large areas recorded significant differences in the average SPI values compared with the remaining years. Thus, for most of Scandinavia the SPI averages are close to zero. Nevertheless, over the period of 1951-2000 there were dominantly positive SPI averages for all of Scandinavia, which differs from other years. This shows the strength of the influence of positive phases of the NAO on the SPI. In contrast, negative phases of the NAO show a weaker influence on the SPI during the second half of the twentieth century. For Scandinavia, over the period of 1901-50, negative phases resulted in negative SPI averages that differed significantly from those obtained for other years. Nevertheless, the average SPI values for this region during the period 1951-2000 are close to zero. This explains the positive differences in SPI values associated with negative phases of the wintertime NAO during the periods of 1951-2000 and 1901-50.

- Region 2 (large areas of central Europe, including Germany, the Czech Republic, Holland, northern Austria, and Poland) also shows reinforcement of the influence of positive phases of the NAO, which tend to produce more strongly positive values of the SPI, mainly between the months of March and June. In contrast, during negative phases, negative differences in the SPI are dominant at all time scales.

- In region 4 (large areas of France and the northern Iberian Peninsula), there is a weak increase in the impact of positive phases of the NAO during 1951- 

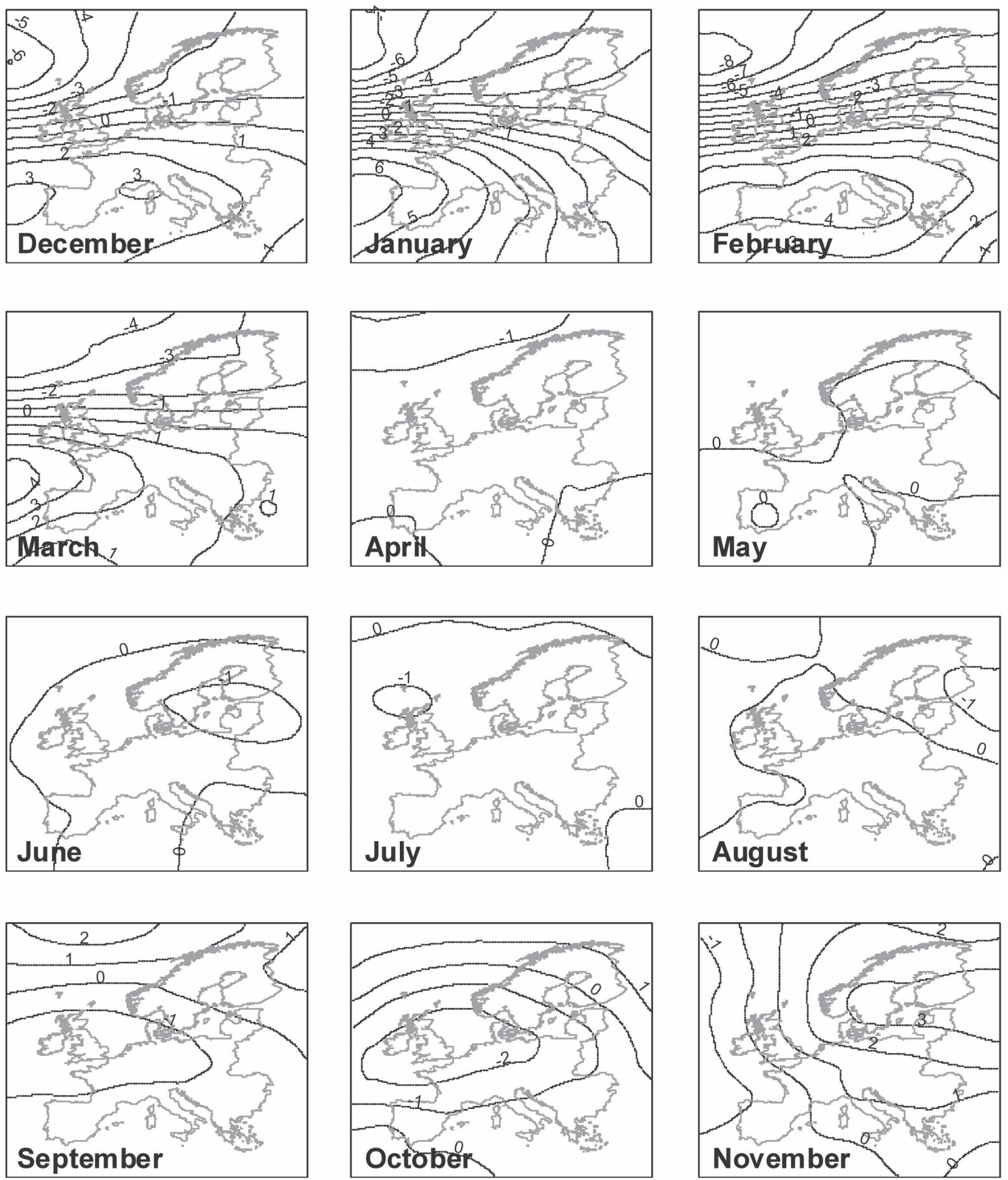

FIG. 10. Average anomalies of SLP (differences regarding the average) during the positive extreme phases of the NAO are shown.

2000 (positive difference in the SPI values between the two periods). The differences observed during the negative phases of the two periods are more important, however, because they show a very important decrease in values of the SPI (see Fig. 14). In contrast, negative phases during the period of 1951-2000 did not lead to an increase in the SPI because the average values were close to zero. 

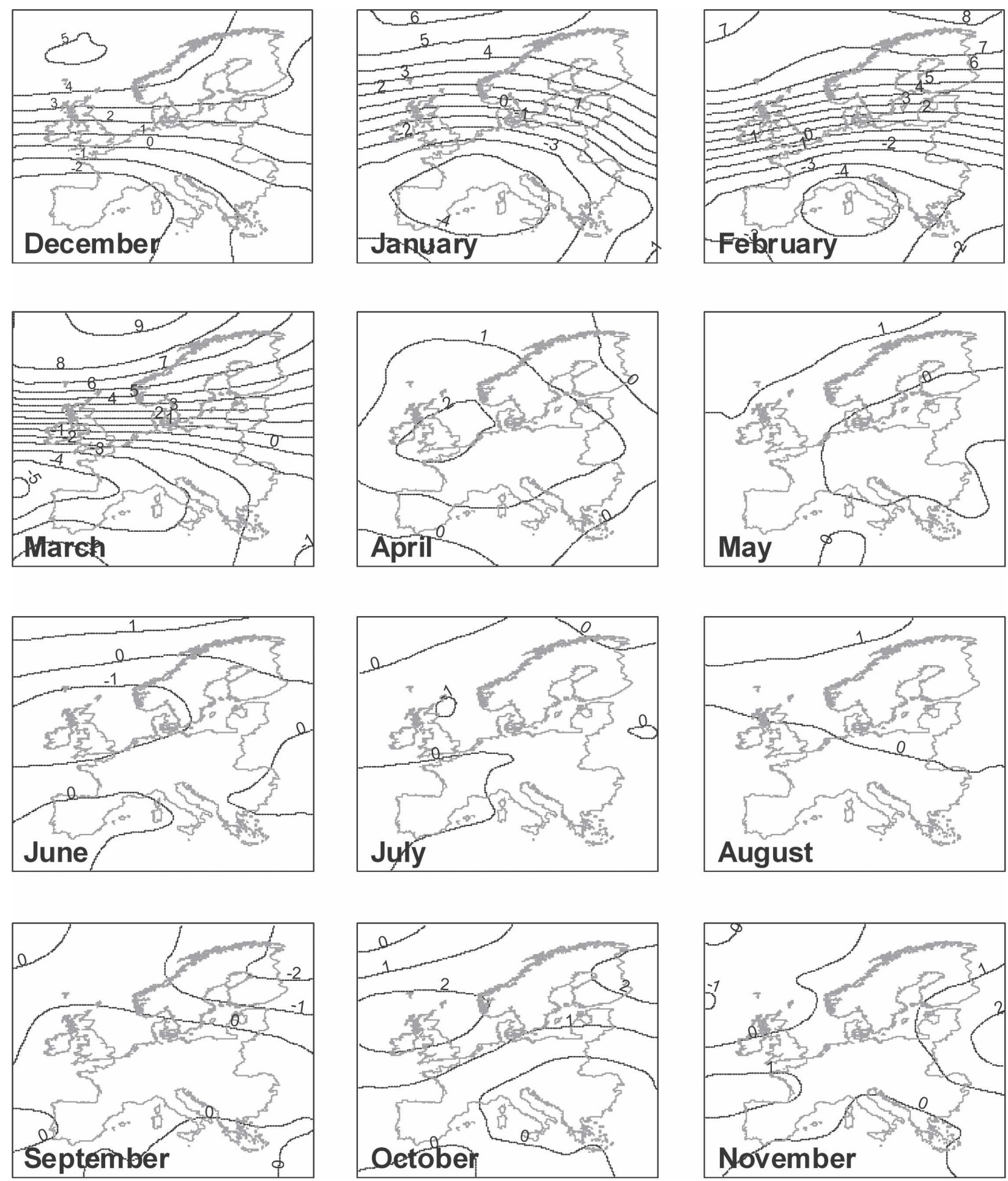

FIG. 11. Average anomalies of SLP (differences regarding the average) during the negative phases of the NAO are shown.

- Region 5 (a large part of the British Isles) also records dominantly positive differences in the SPI averages for the periods of 1901-50 and 1951-2000, indicating that positive phases were more likely to produce positive values of the SPI in the second half of the twentieth century. In contrast, during negative phases the average SPI values are largely similar between the 1901-50 and 1951-2000 analysis periods. 

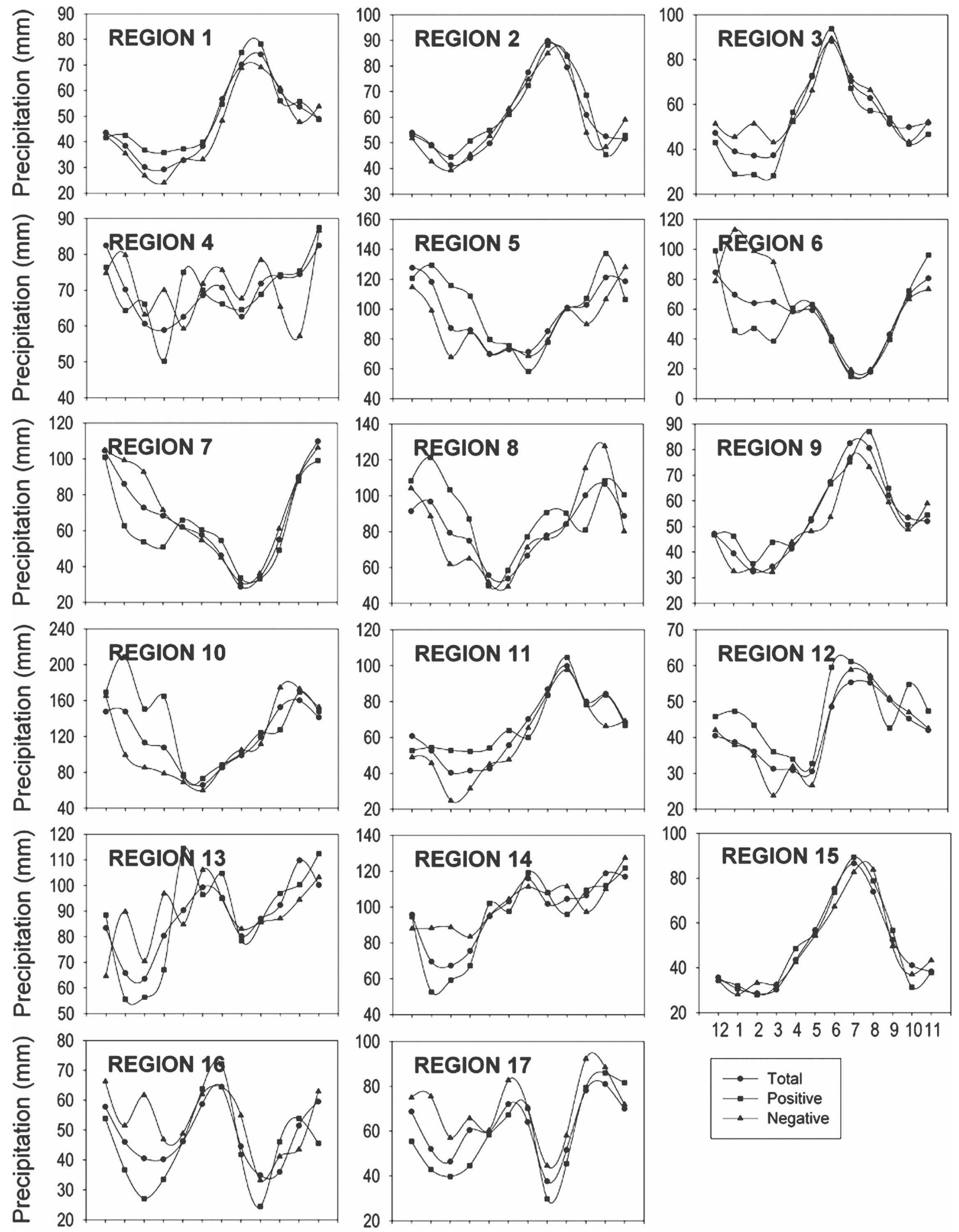

121234567891011

121234567891011

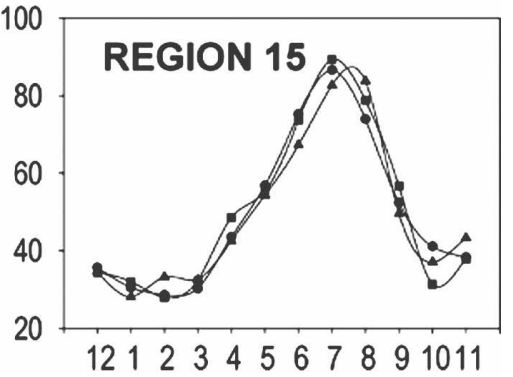

FIG. 12. Monthly average precipitation corresponding to the positive and negative phases of the NAO is shown. Also, the average over the whole period is shown (1901-2000). The number of each region corresponds to those shown in Fig. 4. 
A)
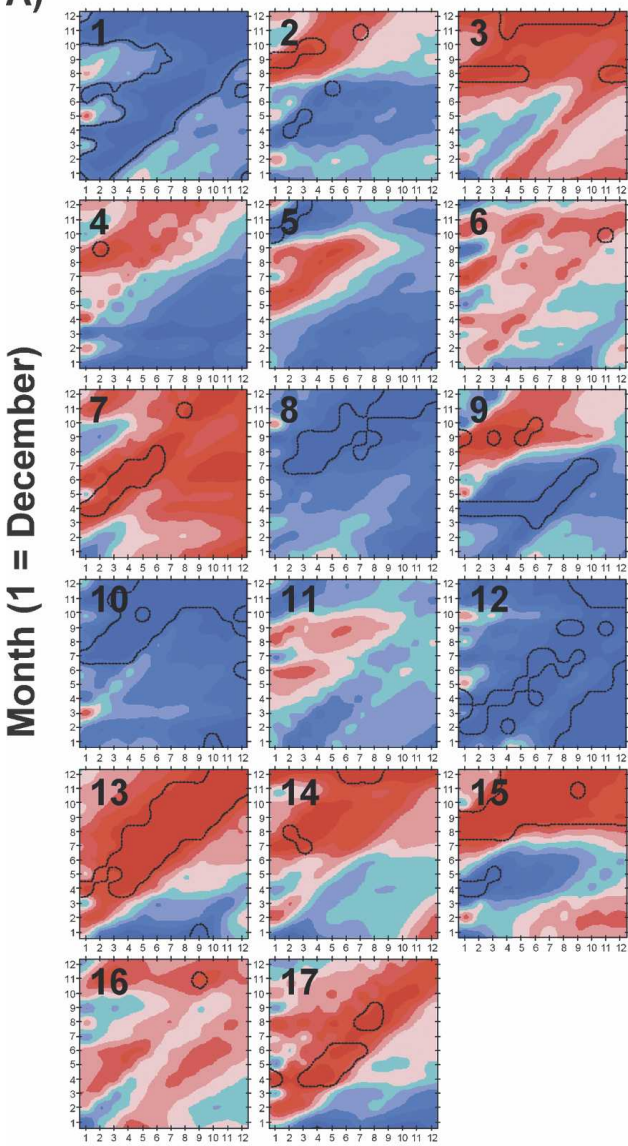

SPI (time scale)

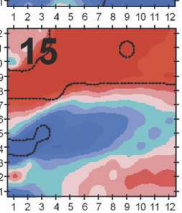

B)
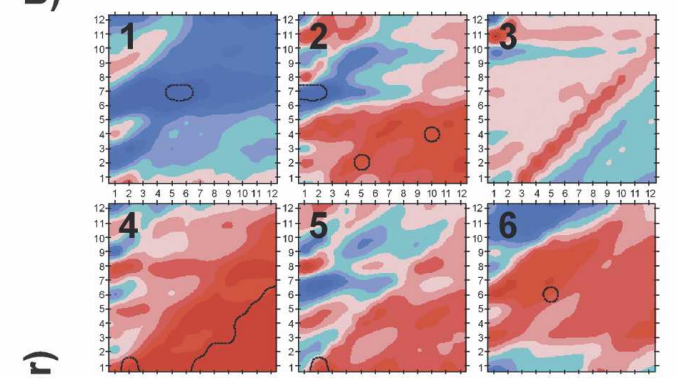

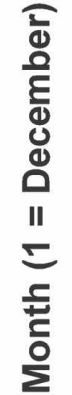
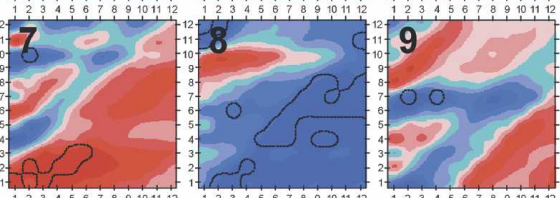

$<-0.8$

-0.8 to -0.6

-0.6 to -0.4

-0.4 to -0.2

-0.2 to 0

0 to 0.2

0.2 to 0.4

0.4 to 0.6

0.6 to 0.8

$>0.8$
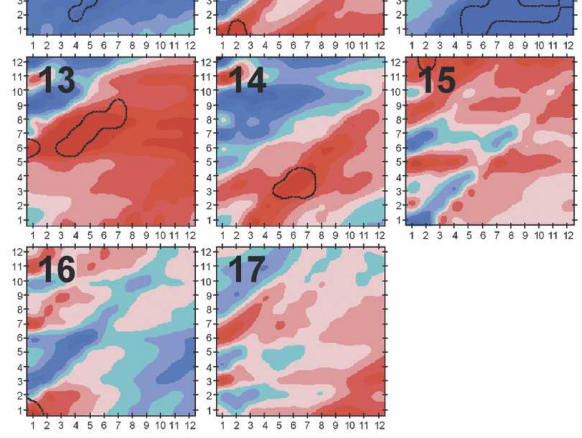

SPI (time scale)

FIG. 13. The difference [(1951-2000) - (1901-50)] in the average values of SPI at time scales from 1 to 12 months between December (1) and November (12) during the (a) positive and (b) negative extreme phases of the NAO in the 17 homogeneous regions is shown. Black lines indicate significant differences $(\alpha<0.05)$ between the average SPI during the positive and negative years between the first and the second half of the twentieth century.

- Region 6 (most of the Iberian Peninsula) records the most important influence of positive and negative phases of the NAO over the twentieth century (Fig. 8). This behavior was very stable during the entire analysis period, with differences between the two periods being close to zero, especially during positive phases.

- Region 7 (southern Italy, Greece, and large areas of the Balkans) records clear differences in average SPI values between the periods of 1901-50 and 1951-2000 for both positive and negative NAO phases. There are dominantly strong $(<-0.5)$ negative differences in the SPI values as a consequence of the increasing influence of positive phases on the SPI during recent decades. The opposite pattern is observed during negative phases, whose influence decreased over this period.

- Region 13 (northern Italy) shows a very clear pattern that consists of strong negative differences in SPI anomalies corresponding to positive phases of the NAO for the periods of 1951-2000 and 1901-50. The same behavior, although less intense, is observed during negative phases. This region records the most important changes between the first and second halves of the twentieth century in terms of the influence of positive phases of the NAO on the SPI. The same behavior is also observed in region 17 (the south of France and northeastern Spain); however, in this region the temporal trend is the opposite to that recorded in Italy: negative differences indicate that the influence of the positive phases of the NAO was weak during 1901-50 and strong during 1951-2000.

To explain the observed spatial patterns of the influence of positive and negative phases of the NAO on the SPI during the 1901-50 and 1951-2000 periods, we calculated the differences in the average wintertime SLPs 


\section{POSITIVE}
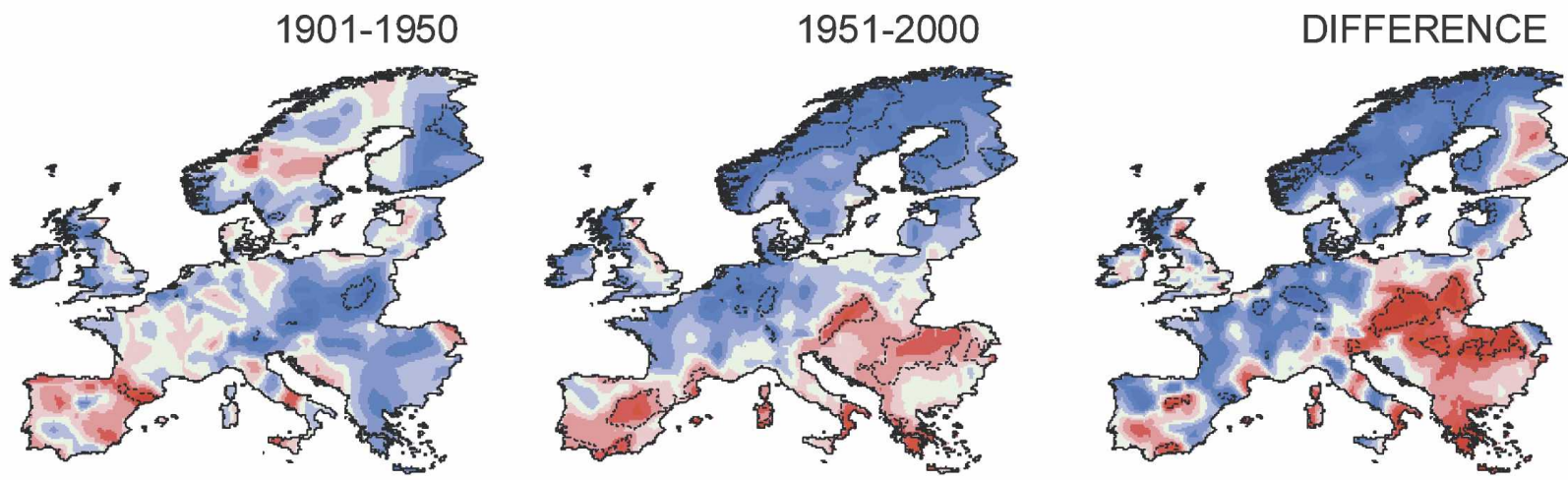

\section{NEGATIVE}
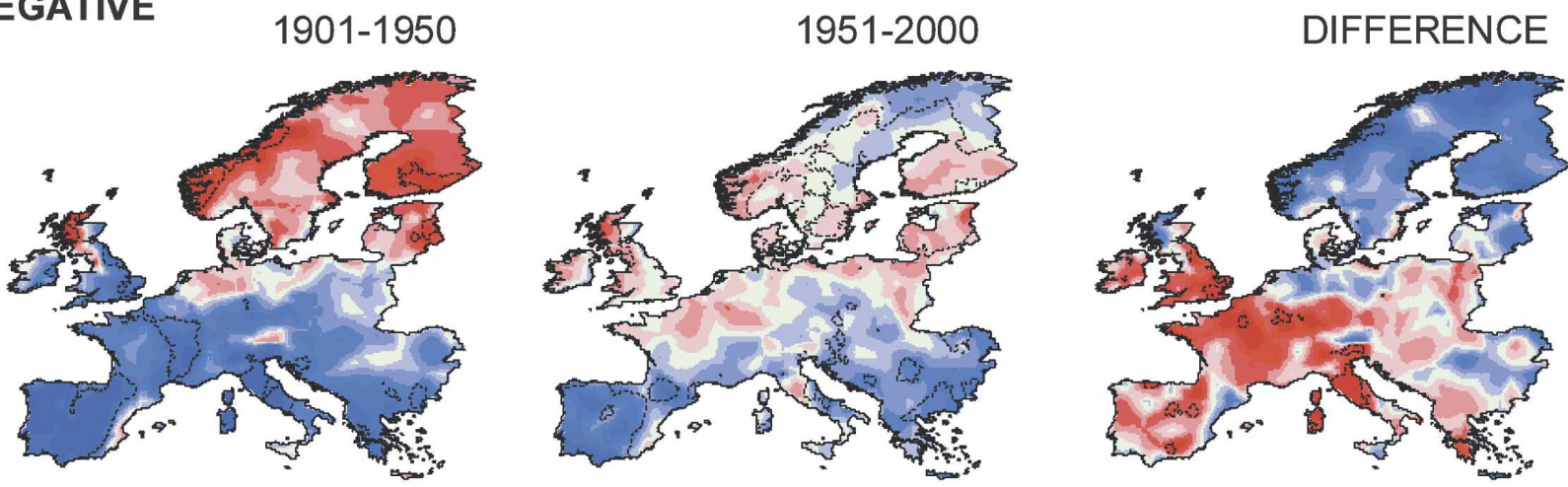

\section{$\begin{array}{lllllllllll}-1.0 & -0.8 & -0.6 & -0.4 & -0.2 & 0.0 & 0.2 & 0.4 & 0.6 & 0.8 & 1.0\end{array}$}

FIG. 14. Average values of SPI ${ }_{12}$ in August during the positive and negative phases of the winter NAO in the 1901-50 and 1951-2000 periods are shown. Also, the difference between both periods is shown. Black lines indicate significant differences $(\alpha<0.05)$ between the SPI average during the positive/negative phases of the NAO and the rest of the years (normal and the opposite sign), and also between the first and the second half of the twentieth century for the maps of the differences.

for the two periods. Figure 15 shows these differences for positive (Fig. 15a) and negative (Fig. 15b) phases.

During positive phases, there is a clear spatial configuration that is similar for all months except February. The differences recorded between the first and second halves of the twentieth century indicate a reduction in pressure (average decrease from -2 to $-6 \mathrm{hPa}$ ) in Scandinavia for positive phases. In contrast, an increase in pressure (from 2 to $6 \mathrm{hPa}$ ) was recorded for southwestern Europe. During positive phases in the second half of the twentieth century, these changes reinforced flows from the northwest, and these flows affected most of Europe. This reinforcement was most pronounced in March.

The regions subjected to these flows (Scandinavia, the northwest parts of the United Kingdom, and areas of central Europe) were regions that recorded an increase in SPI during positive phases of the NAO.
For large areas of eastern Europe, the reduction in SPI values during positive phases can also be explained by changes in the SLP configurations, because precipitation in this sector is not driven by northwest flows, which have increased during the positive phases between the first and second halves of the twentieth century. Figure 15b shows the differences in the average SLP values corresponding to negative phases of the NAO during the first and second halves of the twentieth century. The figure reveals a decrease in SLP values in northern Europe, mainly in Scandinavia, and an increase in central and southern Europe. These results indicate the attenuation of the pressure fields, which is typically associated with negative phases of the NAO during winter. This explains the generally reduced impact of negative NAO phases recorded in the most of the considered regions. The opposite pattern is observed for positive NAO phases. Although the spatial 
A)
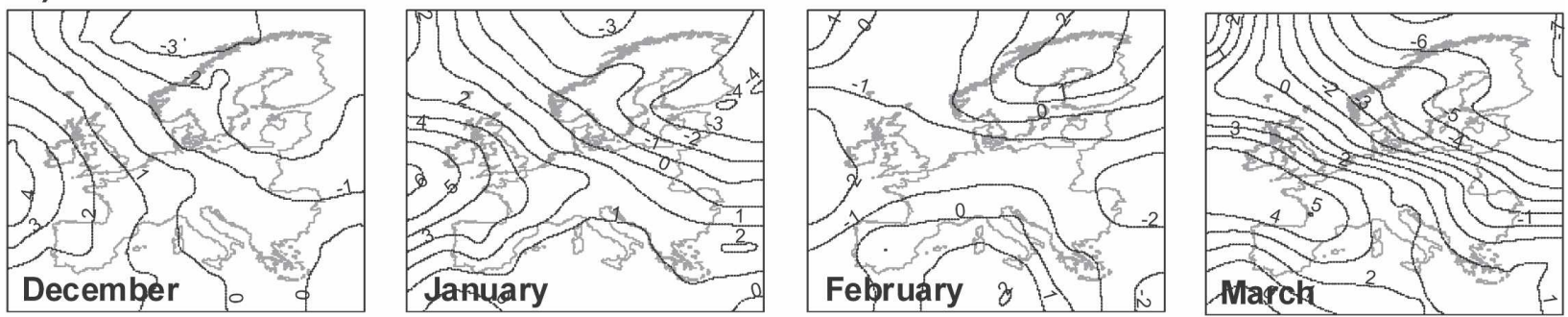

B)
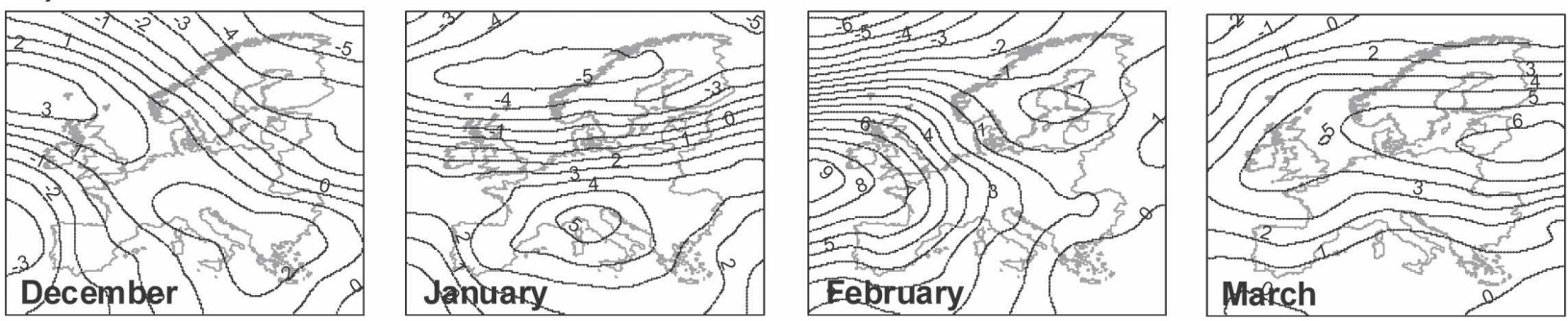

FIG. 15. Differences in the average anomalies of SLP during the (a) positive and (b) negative extreme phases of the NAO between the 1951-2000 and 1901-50 periods are shown.

patterns of SLP and associated flows vary between different months, Scandinavia recorded a strengthening of northwest and west flows that explains the arrival of more humid influences to the region and an increase in SPI values. The decrease in SPI values recorded over large areas of western and central Europe is possibly related to the generally positive SLP differences recorded in this region during the negative phases.

\section{Discussion and conclusions}

The results of our analysis demonstrate that the response of droughts to positive and negative phases of the NAO vary spatially and also depend on the month and decade and time scale of the SPI. In general, during positive phases, negative SPI averages are recorded in southern Europe and positive averages are recorded in northern Europe (Scandinavia and the United Kingdom), whereas the opposite trends occur during negative phases. This observation is in agreement with the general and widely known behavior of the effects of the NAO on precipitation throughout the entire European continent (e.g., Hurrell and Van Loon 1997; Trigo et al. 2002).

Beyond the general spatial variations in the influence of the NAO on precipitation throughout Europe, this paper highlights the outstanding influence of positive and negative phases of the wintertime NAO on drought conditions during the succeeding months. Thus, we found significant differences in the SPI averages (com- pared to normal years and years with the opposite sign) for spring, summer, and even autumn months. In the areas of the Iberian Peninsula, southern Italy, and the Balkans, strong negative SPI averages, indicative of severe drought conditions, are recorded in summer and autumn during positive phases, when medium and long time scales of SPI (6-12 months) are considered. The same trends are recognized for Sweden, Finland, Lithuania, Latvia, and western Norway as a response to the negative phases of the NAO. The fact that this behavior is found in several regions is indicative of the important impact of positive and negative phases of the wintertime NAO on usable water sources throughout the year. In other regions, negative average values of SPI are recorded at shorter time scales (2-5 months) during the spring (e.g., large eastern European regions during positive phases of the NAO and southern Norway during negative phases).

We have found that there is a prevalence of either maximum or minimum values of the SPI along the diagonal shown in Fig. 8, with some differences depending on the regions. This fact is related to the importance of winter precipitation regarding to the total annual amounts. In southern Europe, where the bulk of the precipitation comes during winter, differences in winter precipitation between positive and negative phases is very important (shown in Fig. 12), and this behavior has a noticeable impact on drought condition during the succeeding months. Nevertheless, the same is true in large areas of Fennoscandia and the Baltic states, 
where the precipitation maxima occur during late summer. The reason for this might also be related to the differences in average winter precipitation between positive and negative phases of NAO in winter. However, differences in the winter precipitation as a function of the sign of the NAO are less important than that observed in southern Europe, and reinforcement and maintenance of droughts throughout the year may be also related to less precipitation in summer during the negative NAO phases in winter, as shown in Fig. 12.

Previous studies have shown that the time scales of the SPI have a direct relationship with usable water sources, such as soil moisture, river discharge, and reservoir storage (Vicente-Serrano and López-Moreno 2005; Vasiliades and Loukas 2006). In general, the long time scales of the SPI are related to reservoir storage and river discharge, whereas short time scales are related to variability in soil moisture (Sims et al. 2002). Therefore, positive phases of the NAO lead to drought conditions in terms of soil moisture during winter and spring and hydrological droughts (reduction in river discharge and the levels of reservoir storages) in summer and autumn in regions within southern Europe. In northern Europe, these trends occur during negative phases.

The above results are in agreement with the observed response of hydrological systems to the NAO in several European regions. Cherry et al. (2005) described how negative phases of the NAO have a strong negative impact on river flow and hydropower production in Scandinavia. Wedgbrow et al. (2002) demonstrated a negative relationship between the wintertime NAO index and summertime river flow rates in Britain. Hyvärinen (2003) found relationships between summertime flow rates and the wintertime NAO in Finland and Iceland, respectively. In a study of southern Europe, Trigo et al. (2004) documented a lag time of 2-3 months in the response of river discharge to NAO positive and negative phases in the Atlantic basins of the Iberian Peninsula. In a study of the Tagus basin within the Iberian Peninsula, López-Moreno et al. (2007), reported that the impact of positive and negative phases of the NAO on river discharge and the levels of storage reservoirs is neither instantaneous nor restricted to the winter months. Thus, the decrease in the amount of water stored in the reservoirs during negative phases of the NAO is especially severe during the summer and autumn, whereas in winter and spring the amount of stored water is similar to that of normal years. Accordingly, clear anomalies in average SPI values calculated at medium-long time scales observed for several regions during the summer and autumn agree with the observed response of river discharge and the levels of storage reservoirs to the NAO in the same regions. This raises the possibility of the joint use of the NAO index and the SPI as a means of predicting and monitoring hydrological droughts in these areas.

Previous authors have shown a connection between wintertime circulation patterns and patterns of atmospheric circulation in other months (Ogi et al. 2004). Although Ogi et al. (2003) described the impact of the wintertime NAO on summertime atmospheric circulation, this is not evident in the positive and negative phases analyzed throughout the twentieth century. We failed to observe clear patterns of SLP during the months following positive and negative winters of the NAO. Accordingly, the anomalies in average SPI values found at medium-long time scales in spring, summer, and autumn in certain regions, mainly in southwestern Europe, are related to the important influence of positive and negative phases of the NAO on wintertime precipitation, which leads to significant differences in the total amount of precipitation that occurs during the positive and negative phases.

Another important result observed for multiple regions is the fact that the magnitude of anomalies in average SPI values differs between positive and negative phases of the NAO. This indicates the asymmetric response of droughts to the NAO. The asymmetric influence of the NAO on other climate variables has been identified over all of Europe for temperature (PozoVázquez et al. 2001) and solar radiation (Pozo-Vázquez et al. 2004).

Several examples of the asymmetric response of climate to atmospheric circulation patterns can be observed. Thus, the drought response to El Niño-Southern Oscillation in Europe is markedly asymmetric (see Vicente-Serrano 2005, and references therein), which is related to the different anomalies in the pressure patterns corresponding to El Niño and La Niña years (Pozo-Vázquez et al. 2005). Also, for the NAO, some asymmetric effects on precipitation have been observed in Europe, which could explain the asymmetric response of droughts throughout the year observed in this study. Muñoz-Díaz and Rodrigo (2003, 2004) showed that in Spain there are noticeable changes in the total amount of precipitation as a function of the positive and negative phases of the NAO, but there is also an important change in the probability of occurrence of climate categories of rainfall. Thus, Gallego et al. (2005) have shown that the strong influence of the NAO on southern Europe is mainly due to the effect of the winter NAO on intense rainfall events, which are more frequent during the negative extreme phases. The opposite would occur in northern Europe, with a 
greater frequency of extreme events corresponding the positive phases (Haylock and Goodess 2004). Recently, Pires and Perdigão (2007) have assessed asymmetry within the statistical response of the winter precipitation to the NAO over the North Atlantic-European region. They found that near the central North Atlantic, around $40^{\circ} \mathrm{N}, 20^{\circ} \mathrm{W}$, and southeast of Iceland, the correlation is much stronger in the wet-favorable regime, with negative phases of the NAO in the first location and positive phases in the second location. On the contrary, around $42^{\circ} \mathrm{N}, 48^{\circ} \mathrm{W}$ in the western North Atlantic and in the western Mediterranean near $36^{\circ} \mathrm{N}$, the correlation is only relevant for the dry-favorable positive phases. These authors have shown that there are some coherent regions where the nonlinear component of the response of winter precipitation to the NAO is more important. Moreover, the detected asymmetric response can be also related to asymmetries in the geopotential height as a function of the positive and negative phases. Thus, Wu et al. (2006) demonstrated an asymmetric relationship between the Arctic Oscillation (AO) and the wintertime climate of North America. The authors showed that the $500-\mathrm{mb}$ geopotential height (Z500) and surface air temperature (SAT) anomalies reveal a pronounced asymmetry in the atmospheric patterns associated with positive and negative phases of the AO.

Finally, we also documented that the effects of positive and negative phases of the NAO on droughts within the European continent at different time scales were not stable during the twentieth century. In general, the influence of positive phases of the NAO on droughts is strengthened in the second half of the twentieth century compared to the influence in the period of 1901-50. In contrast, the negative phases of the wintertime NAO show a weaker influence on the SPI during the second half of the twentieth century. This behavior is related to changes in the SLP patterns associated with positive and negative phases of the NAO during the first and second halves of the twentieth century. The pattern shows a reinforcement of negative pressure anomalies and more frequent strong northwest flows associated with positive phases of the NAO during the second half of the twentieth century. The main consequence of these trends is an increase in the frequency of humid conditions in northern Europe (Scandinavia, the United Kingdom, and northern Germany), and an increase in the frequency of drought conditions in area of southern Europe, including the Iberian Peninsula.

Negative phases also recorded strong northwest and north flows and an increase in SLP over large areas of western and central Europe. This trend explains the observation that less humid conditions were recorded in central and southern Europe during the negative phases of the NAO in the second half of the twentieth century. This trend also explains the fact that negative SPI values recorded for northern Europe were not recognized as a response to these phases in the second half of the century.

The northern European areas, where a significant positive trend in annual precipitation is recorded, represent the areas that record the main changes in the influence of positive and negative phases of the NAO on droughts throughout the twentieth century. These changes include an increase in the frequency of humid conditions in response to positive phases and a decrease in the frequency of dry conditions in response to negative phases. These observations highlight the important role of the positive and negative phases of the NAO, and temporal variations in the phases, in explaining the positive trend toward more humid conditions that is recorded in some northern regions.

The observed temporal changes in the influence of the NAO on different key climate parameters in Europe have been identified previously (e.g., Polyakova et al. 2006; Chen and Hellström 1999; Slonosky et al. 2001; Jones et al. 2003; Osborn et al. 1999), but there has not been a definitive explanation to provided the physical causes or the connections of this behavior. Slonosky et al. (2001) showed that periods of high or low correlation between NAO and climate variables in Europe are not systematically associated with the mean strength or variability of the circulation. Nevertheless, these authors showed a $50-60-y r$ cycle in the strength of the correlation of temperatures and NAO in northern Europe, which might possibly be related to North Atlantic air-sea dynamics, or variability in the themohaline circulation, an interesting result given the 50 -yr cycles in the model studies of the convective overturning of the thermohaline circulation in the northern North Atlantic (Delworth et al. 1993).

Moreover, it is possible that these changes in the circulation-climate relationships are caused by external climate forcing, such as volcanic activity. Variations in local climate may be responding to changes in circulation index strength, but may also be due to competing influences from other circulation types. In the present paper, we have shown that the instability of the influence of the NAO is related to changes in the characteristics of the positive and negative phases, which in turn lead to modifications in SLP patterns associated to the NAO phases between the first and second half of the twentieth century. Portis et al. (2001) showed that position and intensity of main pressure centers that characterize NAO change noticeably between season, which is also the case for the NAO-climate relation- 
ships. The observed modifications in the SLP patterns corresponding to the positive and negative phases of the NAO between the first and the second half of the twentieth century might also suggest interdecadal changes in the position of these main pressure centers, explaining observed changes in the NAO-drought relationships. In any case, further work remains to be done to investigate the circulation dynamics, which may cause the nonstationary influence of the NAO on climate. Although teleconnection indices such as the NAO have been widely used to predict drought conditions with a high degree of reliability (e.g., Cordery and McCall 2000; Rodwell 2003), we have demonstrated an important instability in the influence of positive and negative phases of the NAO on Europe-wide droughts. This instability complicates the prediction and management of droughts based solely on the wintertime NAO index. Further research is needed to determine the factors that control temporal changes in the influence of NAO phases on droughts. Moreover, other teleconnection patterns, such as ENSO (Vicente-Serrano 2005; Lloyd-Hughes and Saunders 2002a) and east Atlanticwest Russia (EAWR; Krichak and Alpert 2005), also have an important influence on variability in precipitation and droughts in some European regions.

Acknowledgments. We thank the Tyndall Center for Climate Change Research and Dr. Tim Mitchell for providing the precipitation database used in this study. This work has been supported by the following projects: CGL2005-04508/BOS (financed by the Spanish Commission of Science and Technology and FEDER), PIP176/2005 (financed by the Aragón Government), and "Programa de grupos de investigación consolidados" (BOA 48 of 20-04-2005), also financed by the Aragón Government. Research of the first author was supported by postdoctoral fellowship by the Ministerio de Educación (Spain).

\section{REFERENCES}

Abramowitz, M., and I. A. Stegun, 1965: Handbook of Mathematical Functions. Dover Publications, 1046 pp.

Bordi, I., K. Fraedrich, F.-W. Gerstengarbe, P. C. Werner, and A. Sutera, 2004: Potential predictability of dry and wet periods: Sicily and Elbe-Basin (Germany). Theor. Appl. Climatol., 77, 125-138.

Briffa, K. R., P. D. Jones, and M. Hulme, 1994: Summer moisture variability across Europe, 1892-1991: An analysis based on the Palmer Drought Severity Index. Int. J. Climatol., 14, 475506.

Changnon, S. A., and W. E. Easterling, 1989: Measuring drought impacts: The Illinois case. Water Resour. Bull., 25, 27-42.

Chen, D., and C. Hellström, 1999: The influence of the North Atlantic Oscillation on the regional temperature variability in
Sweden: Spatial and temporal variations. Tellus, 51A, 505516.

Cherry, J., H. Cullen, M. Visbeck, A. Small, and C. Uvo, 2005: Impacts of the North Atlantic Oscillation on Scandinavian hydropower production and energy markets. Water Resour. Manage., 19, 673-691.

Cordery, I., and M. McCall, 2000: A model for forecasting drought from teleconnections. Water Resour. Res., 36, 763-768.

Delworth, T., S. Manabe, and R. J. Stouffer, 1993: Interdecadal variations of the thermohaline circulation in a coupled ocean-atmosphere model. J. Climate, 6, 1993-2011.

Eltahir, E. A. B., and P. J. F. Yeh, 1999: On the asymmetric response of aquifer water level to floods and droughts in Illinois. Water Resour. Res., 35, 1199-1217.

Gallego, M. C., J. A. García, and J. M. Vaquero, 2005: The NAO signal in daily rainfall series over the Iberian Peninsula. Climate Res., 29, 103-109.

Guttman, N. B., 1998: Comparing the Palmer Drought Index and the Standardized Precipitation Index. J. Amer. Water Resour. Assoc., 34, 113-121.

_- 1999: Accepting the Standardized Precipitation Index: A calculation algorithm. J. Amer. Water Resour. Assoc., 35, 311-322.

_ J. R. Wallis, and J. R. M. Hosking, 1992: Spatial comparability of the Palmer Drought Severity Index. Water Resour. Bull., 28, 1111-1119.

Hayes, M. J., M. D. Svoboda, D. A. Wilhite, and O. V. Vanyarkho, 1999: Monitoring the 1996 drought using the Standardized Precipitation Index. Bull. Amer. Meteor. Soc., 80, 429-438.

Haylock, M. R., and C. M. Goodess, 2004: Interannual variability of European extreme winter rainfall and links with mean large-scale circulation. Int. J. Climatol., 24, 759-776.

Heim, R. R., 2002: A review of twentieth-century drought indices used in the United States. Bull. Amer. Meteor. Soc., 83, 11491165 .

Helsel, D. R., and R. M. Hirsch, 1992: Statistical Methods in Water Resources. Elsevier, 522 pp.

Hosking, J. R. M., 1990: L-moments: Analysis and estimation of distributions using linear combinations of order statistics. J. Roy. Stat. Soc., 52B, 105-124.

Hurrell, J. W., 1995: Decadal trends in North Atlantic Oscillation: Regional temperatures and precipitation. Science, 269, 676679.

— sociated with the North Atlantic Oscillation. Climatic Change, 36, 301-326.

—, Y. Kushnir, G. Ottersen, and M. Visbeck, 2003: An overview of the North Atlantic Oscillation. The North Atlantic Oscillation: Climate Significance and Environmental Impact, Geophys. Monogr., Vol. 134, Amer. Geophys. Union, 1-36.

Hyvärinen, V., 2003: Trends and characteristics of hydrological time series in Finland. Nordic Hydrol., 34, 71-90.

Ji, L., and A. J. Peters, 2003: Assessing vegetation response to drought in the northern Great Plains using vegetation and drought indices. Remote Sens. Environ., 87, 85-98.

Jolliffe, I. T., 1990: Principal component analysis: A beginner's guide. Part I: Introduction and application. Weather, 45, 375382.

Jones, P. D., T. Jónsson, and D. Wheeler, 1997: Extension to the North Atlantic Oscillation using early instrumental pressure observations from Gibraltar and south-west Iceland. Int. J. Climatol., 17, 1433-1450. 
— , T. J. Osborn, and K. R. Briffa, 2003: Pressure-based measures of the North Atlantic oscillation (NAO): A comparison and an assessment of changes in the strength of the NAO and in its influence on surface climate parameters. The North Atlantic Oscillation: Climate Significance and Environmental Impact, Geophys. Monogr., Vol. 134, Amer. Geophys. Union, $51-62$.

Karl, T. R., and A. J. Koscielny, 1982: Drought in the United States: 1895-1981. J. Climatol., 2, 313-329.

Keyantash, J., and J. Dracup, 2002: The quantification of drought: an evaluation of drought indices. Bull. Amer. Meteor. Soc., 83, 1167-1180.

Krichak, S. O., and P. Alpert, 2005: Decadal trends in the east Atlantic-west Russia pattern and Mediterranean precipitation. Int. J. Climatol., 25, 183-192.

Lana, X., C. Serra, and A. Burgueño, 2001: Patterns of monthly rainfall shortage and excess in terms of the Standardized Precipitation Index for Catalonia (NE SPain). Int. J. Climatol., 21, 1669-1691.

Lanzante, J. R., 1996: Resistant, robust, and non-parametric techniques for the analysis of climate data: Theory and examples, including applications to historical radiosonde station data. Int. J. Climatol., 16, 1197-1226.

Lloyd-Hughes, B., and M. A. Saunders, 2002a: Seasonal prediction of European spring precipitation from El Niño-Southern Oscillation and local sea-surface temperatures. Int. J. Climatol., 22, 1-14.

$\longrightarrow$, and -2002 b: A drought climatology for Europe. Int. J. Climatol., 22, 1571-1592.

López-Moreno, J. I., S. Beguería, S. M. Vicente-Serrano, and J. M. García-Ruiz, 2007: Influence of the North Atlantic Oscillation on water resources in central Iberia: Precipitation, streamflow anomalies, and reservoir management strategies. Water Resour. Res., 43, W09411, doi:10.1029/2007WR005864.

Loukas, A., and L. Vasiliades, 2004: Probabilistic analysis of drought spatiotemporal characteristics in Thessaly region, Greece. Nat. Hazards Earth Syst. Sci., 4, 719-731.

McKee, T. B., N. J. Doesken, and J. Kleist, 1993: The relationship of drought frequency and duration to time scales. Preprints, Eighth Conf. on Applied Climatology, Anaheim, CA, Amer. Meteor. Soc., 179-184.

Mitchell, T. D., and P. D. Jones, 2005: An improved method of constructing a database of monthly climate observations and associated high-resolution grids. Int. J. Climatol., 25, 693-712.

Muñoz-Díaz, D., and F. S. Rodrigo, 2003: Effects of the North Atlantic oscillation on the probability for climatic categories of local monthly rainfall in Southern Spain. Int. J. Climatol., 23, 381-397.

$\longrightarrow$, and - 2004: Impacts of the North Atlantic Oscillation on the probability of dry and wet winters in Spain. Climate Res., 27, 33-43.

Ogi, M., Y. Tachibana, and K. Yamazaki, 2003: Impact of the wintertime North Atlantic Oscillation (NAO) on the summertime atmospheric circulation. Geophys. Res. Lett., 30, 1704, doi:10.1029/2003GL017280.

—, K. Yamazaki, and Y. Tachibana, 2004: The summertime annular mode in the Northern Hemisphere and its linkage to the winter mode. J. Geophys. Res., 109, D20114, doi:10.1029/ 2004JD004514.

Osborn, T. J., K. R. Briffa, S. F. B. Tett, P. D. Jones, and R. M. Trigo, 1999: Evaluation of the North Atlantic Oscillation as simulated by a coupled climate model. Climate Dyn., 15, 685702 .
Palmer, W. C., 1965: Meteorological droughts. U.S. Dept. of Commerce Weather Bureau Res. Paper 45, 58 pp.

Pandey, R. P., and K. S. Ramasastri, 2001: Relationship between the common climatic parameters and average drought frequency. Hydrol. Process., 15, 1019-1032.

Pires, C. A., and R. A. P. Perdigão, 2007: Non-Gaussianity and asymmetry of the winter monthly precipitation estimation from the NAO. Mon. Wea. Rev., 135, 430-448.

Polyakova, E. I., A. G. Journel, I. V. Polyakov, and U. S. Bhatt, 2006: Changing relationship between the North Atlantic Oscillation and key North Atlantic climate parameters. Geophys. Res. Lett., 33, L03711, doi:10.1029/2005GL024573.

Portis, D. H., J. E. Walsh, M. El Hamly, and P. J. Lamb, 2001: Seasonality of the North Atlantic oscillation. J. Climate, 14, 2069-2078.

Pozo-Vázquez, D., M. J. Esteban-Parra, F. S. Rodrigo, and Y. Castro-Díez, 2001: A study of NAO variability and its possible non-linear influences on European surface temperature. Climate Dyn., 17, 701-715.

_, J. Tovar-Pescador, S. R. Gámiz-Fortis, M. J. Esteban-Parra, and Y. Castro-Díez, 2004: NAO and solar radiation variability in the European North Atlantic region. Geophys. Res. Lett., 31, L05201, doi:10.1029/2003GL018502.

— , S. R. Gámiz-Fortis, J. Tovar-Pescador, M. J. Esteban-Parra, and Y. Castro-Díez, 2005: North Atlantic winter SLP anomalies based on the autumn ENSO state. J. Climate, 18, 97-103.

Redmond, K. T., 2002: The depiction of drought: A commentary. Bull Amer. Meteor. Soc., 83, 1143-1147.

Richman, M. B., 1986: Rotation of principal components. J. Climatol., 6, 293-335.

Rodwell, M. J., 2003: On the predictability of the North Atlantic climate. The North Atlantic Oscillation: Climate Significance and Environmental Impact, Geophys. Monogr., Vol. 134, Amer. Geophys. Union, 173-192.

Sankarasubramanian, A., and K. Srinivasan, 1999: Investigation and comparison of sampling properties of L-moments and conventional moments. J. Hydrol., 218, 13-34.

Siegel, S., and N. J. Castelan, 1988: Nonparametric Statistics for the Behavioral Sciences. 2nd ed. McGraw-Hill, 399 pp.

Sims, A. P., D. S. Nigoyi, and S. Raman, 2002: Adopting indices for estimating soil moisture: A North Carolina case study. Geophys. Res. Lett., 29, 1183, doi:10.1029/2001GL013343.

Slonosky, V. C., P. D. Jones, and T. D. Davies, 2001: Atmospheric circulation and surface temperature in Europe from the 18th century to 1995. Int. J. Climatol., 21, 63-75.

Trenberth, K. E., and D. A. Paolino Jr., 1980: The Northern Hemisphere sea-level pressure data set: Trends, errors, and discontinuities. Mon. Wea. Rev., 108, 855-872.

Trigo, R. M., T. J. Osborn, and J. M. Corte-Real, 2002: The North Atlantic Oscillation influence on Europe: Climate impacts and associated physical mechanisms. Climate Res., 20, 9-17.

, D. Pozo-Vázquez, T. J. Osborn, Y. Castro-Díez, S. GámizFortis, and M. J. Esteban-Parra, 2004: North Atlantic Oscillation influence on precipitation, river flow, and water resources in the Iberian peninsula. Int. J. Climatol., 24, 925-944.

Van der Schrier, G., K. R. Briffa, P. D. Jones, and T. J. Osborn, 2006: Summer moisture variability across Europe. J. Climate, 19, 2818-2834.

Vasiliades, L., and A. Loukas, 2006: Hydrological drought evaluation with the use of meteorological drought indices. Geophysical Research Abstracts, Vol. 8, Abstract 04468.

Vicente-Serrano, S. M., 2005: El Niño and La Niña influence on drought conditions at different time scales in the Iberian 
Peninsula. Water Resour. Res., 41, W12415, doi:10.1029/ 2004WR003908.

_ 2006: Differences in spatial patterns of drought on different time scales: An analysis of the Iberian Peninsula. Water Resour. Manage., 20, 37-60.

— ferent time scales of climatological drought: An evaluation of the standardized precipitation index in a mountainous Mediterranean basin. Hydrol. Earth Syst. Sci., 9, 523-533.

, J. Cuadrat-Prats, and A. Romo, 2006: Early prediction of crop production using drought indices at different time-scales and remote sensing data: Application in the Ebro valley (north-east Spain). Int. J. Remote Sens., 27, 511-518.

Wallace, J. M., 2000: North Atlantic Oscillation/annular mode: Two paradigms-One phenomenon. Quart. J. Roy. Meteor. Soc., 126, 791-805.

Wedgbrow, C. S., R. L. Wilby, H. R. Fox, and G. O'Hare, 2002: Prospects for seasonal forecasting of summer drought and low river flow anomalies in England and Wales. Int. J. Climatol., 22, 219-236.
Wilhite, D. A., and M. H. Glantz, 1985: Understanding the drought phenomenon: The role of definitions. Water Int., 10, 111-120.

Wilks, D. S., 2006. Statistical Methods in the Atmospheric Sciences. 2nd ed. Academic Press, 627 pp.

Wu, A., W. W. Hsieh, A. Shabbar, G. J. Boer, and F. W. Zwiers, 2006: The nonlinear association between the Arctic Oscillation and North American winter climate. Climate Dyn., 26, 865-879.

Wu, H., M. J. Hayes, D. A. Wilhite, and M. D. Svoboda, 2005: The effect of the length of record on the standardized precipitation index calculation. Int. J. Climatol., 25, 505-520.

Xie, P., and P. Arkin, 1997: Global precipitation: A 17-year monthly analysis based on gauge observations, satellite estimates, and numerical model outputs. Bull. Amer. Meteor. Soc., 78, 2539-2558.

Zveryaev, I. I., 2004: Seasonality in precipitation variability over Europe. J. Geophys. Res., 109, D05103, doi:10.1029/ 2003JD003668. 